\title{
Emotional intelligence competencies of department chairs in the West Virginia State Community College System and their faculty members' perceptions of organizational climate
}

\author{
Paul L. Milhoan \\ West Virginia University
}

Follow this and additional works at: https://researchrepository.wvu.edu/etd

\section{Recommended Citation}

Milhoan, Paul L., "Emotional intelligence competencies of department chairs in the West Virginia State Community College System and their faculty members' perceptions of organizational climate" (2007). Graduate Theses, Dissertations, and Problem Reports. 2760.

https://researchrepository.wvu.edu/etd/2760

This Dissertation is protected by copyright and/or related rights. It has been brought to you by the The Research Repository @ WVU with permission from the rights-holder(s). You are free to use this Dissertation in any way that is permitted by the copyright and related rights legislation that applies to your use. For other uses you must obtain permission from the rights-holder(s) directly, unless additional rights are indicated by a Creative Commons license in the record and/ or on the work itself. This Dissertation has been accepted for inclusion in WVU Graduate Theses, Dissertations, and Problem Reports collection by an authorized administrator of The Research Repository @ WVU.

For more information, please contact researchrepository@mail.wvu.edu. 


\title{
Emotional Intelligence Competencies of Department Chairs in the West Virginia State Community College System and Their Faculty Members' Perceptions of Organizational Climate
}

\author{
Paul L. Milhoan \\ Dissertation submitted to the \\ College of Human Resources and Education at \\ West Virginia University \\ in partial fulfillment of the requirements \\ for the degree of \\ Doctor of Education \\ in \\ Education Leadership \\ Ernest R. Goeres, Ph.D., Chair \\ Erik J. Bitterbaum, Ph.D. \\ Neil S. Bucklew, Ph.D. \\ Richard A. Hartnett, Ed.D. \\ Jon Reed, J.D. \\ Richard T. Walls, Ph.D. \\ Department of Educational Leadership \\ Morgantown, West Virginia \\ 2007
}

Keywords: Educational Administration, Emotional Intelligence, Organizational Climate Copyright 2007 Paul L. Milhoan 
Abstract

\title{
Emotional Intelligence Competencies of Department Chairs in the West Virginia State Community College System and Their Faculty Members' Perceptions of Organizational Climate
}

\author{
Paul L. Milhoan \\ The purpose of this study was to determine if a significant relationship \\ exists between faculty members' perceptions of organizational climate and their \\ chairs' emotional intelligence competencies. The organizational climate \\ description questionnaire for academic departments of colleges and universities \\ (OCDQ-HE-Partial) was used to assess faculty members' perceptions of \\ organizational climate. Chairs' emotional intelligence competencies were \\ measured by the Bar-On Emotional Quotient Inventory (EQ-i). Faculty members \\ and chairs were all employees of the West Virginia State Community and \\ Technical College System. \\ The entire population of chairs $(\mathrm{N}=40)$ and the entire population of faculty \\ members in the West Virginia Community and Technical College System \\ $(\mathrm{N}=326)$ were provided surveys. Eighty-three percent of the chairs participated \\ and $51 \%(n=165)$ of the faculty members returned surveys. The Pearson Product \\ Moment Correlation and the chi square test of independence were used in data \\ analysis. An alpha level of .05 served as the level of significance for the study. \\ Results of the study indicated that a statistically significant negative \\ correlation was found between chairs' levels of emotional intelligence and faculty \\ members' perceptions of organizational climate. Results also indicated that \\ chairpersons' emotional intelligence increases with age and a significant negative \\ correlation exists between chairpersons' age, total administrative experience, \\ and administrative experience in the current department or division and their \\ faculty members' perception of organizational climate. Data indicated that there \\ is a statistically significant difference between OCDQ-HE scores for female \\ chairpersons as compared to male chairpersons, and faculty members perceive \\ organizational climate to be more positive for female chairpersons than male \\ chairpersons. Data also indicated a statistically significant negative correlation \\ between the faculty members' teaching experience in the current department or \\ division and their perceptions of organizational climate.
}




\section{Acknowledgements}

The completion of my doctoral program has been a personal and a professional goal that could not have been accomplished without support and encouragement from many special individuals. My heartfelt appreciation is extended to:

Dr. Ernest Goeres, chairperson, became my committee chair when I began the program back in 2002. Through the process, I found his enthusiasm infectious and his advice and support invaluable.

Dr. Erik Bitterbaum, outside committee member, was formerly the President at WVU-Parkersburg. Dr. Bitterbaum was always quick to offer me support and words of encouragement in my pursuit of the doctorate. Long before I became Chair of the Technology Division at WVU-Parkersburg, he predicted that one day I would become chair of that division.

Dr. Neil Bucklew, formerly President of WVU and chair of my minor area, assisted and advised me as I completed the graduate business capstone course in order to fulfill the requirements of my minor area. I thoroughly enjoyed the capstone course with him as instructor and the research project with the teamwork and camaraderie of the graduate students.

Dr. Richard Hartnett, committee member, who taught the majority of my doctoral-level courses. He maintained a high academic bar in all of his courses and he strived to engage us in the pursuit of academic excellence. 
Dr. Jon Reed, committee member, with whom I felt an instant bond and intellectual connection. I thoroughly enjoyed his graduate-level law courses, and I have had more than one opportunity to use the knowledge that I gained from taking his courses in my role as division chair.

Dr. Richard Walls, committee member, for his willingness to critique my chapters four and five and interpretation of the data. I appreciate his helpful suggestions, and most of all, his patience.

My family, especially my wife, I am thankful for their unconditional love, their encouragement, and their undying faith in me. Since I began the doctoral program in 2002, I have missed many family events and outings. Once I finish this chapter of my life, I intend to spend more quality time with my wife, my children, my grand children, and my parents. 


\section{Table of Contents}

ABSTRACT

ACKNOWLEDGMENTS

ii

TABLE OF CONTENTS

iii

LIST OF FIGURES

LIST OF TABLES

vii

CHAPTER 1

INTRODUCTION

Statement of the Problem

Justification/Need for the Study

Limitations of the Study

Definition of Terms

\section{CHAPTER 2}

REVIEW OF LITERATURE

Leadership

Emotional Intelligence 11

Emotional Intelligence, Age, and Gender 17

Emotional Intelligence and Leadership 17

Emotional Intelligence and Higher Education Leadership 19

Emotional Intelligence and Organizational Climate 20

Organizational Climate - Definition and Description 20

Summary 24

CHAPTER 3

RESEARCH METHODS AND PROCEDURES 26

Population 26

Research Questions and Conceptual Models (Matrices) 27

Measuring Emotional Intelligence Competencies 30

Measuring Organizational Climate 31

Scoring EQ-i Instruments $\quad 35$

Scoring OCDQ-HE-Partial Instruments 37

Analysis of Data 37

Schedule of Events 39

CHAPTER 4

40

PRESENTATION AND ANALYSIS OF DATA $\quad 40$

DESCRIPTIVE DATA $\quad 41$

Department Chair Data $\quad 41$

Faculty Data 42

Emotional Intelligence Competencies 42

Organizational Climate $\quad 42$

STATISTICAL ANALYSES

MAJOR FINDINGS 43

Chairs' Overall Emotional Quotient (EQ) and Organizational Climate 44

Chairs' EQ Subcategories and Organizational Climate Subcategories 45

Chairs' Age and Experience and Emotional Quotient (EQ) 50

Chairs' Gender and Emotional Intelligence Competencies 51 
Chairs' Age and Experience and Organizational Climate (OCDQ) 52 Chairs' Gender and Organizational Climate 53

Faculty Members' Age and Experience and Organizational Climate 54

Faculty Members' Gender and Organizational Climate 55

ANCILLARY FINDINGS 56

Chairs' Emotional Intelligence Competencies 56

Chairs' Total Emotional Quotient (EQ) and Gender 57

Chairs' Total Emotional Quotient (EQ) and Age 58

Chairs' Age Groups and Total Emotional Quotient (EQ) 59

Chairs' Total Emotional Quotient (EQ) and Experience 59

Faculty Members' Age and Experience and OCDQ Subcategories $\quad 60$

Faculty Members' Age and Organizational Climate 62

SUMMARY

63

CHAPTER 5

67

SUMMARY, CONCLUSIONS, AND RECOMMENDATIONS 67

Summary of Purpose $\quad 67$

Summary of the Procedures 68

Summary of Descriptive Data $\quad 70$

Summary of Findings $\quad 71$

Conclusions 73

Discussion and Implications $\quad 79$

The Negative Relationship Between EQ and Organizational Climate 83

Recommendations for Further Research 87

REFERENCES

89

95

APPENDIX A: Bar-On Emotional Quotient Inventory 96

APPENDIX B: Organizational Climate Description Questionnaire 99

APPENDIX C: Chair Survey Introduction Letter 105

APPENDIX D: Chairperson Demographics Survey 107

APPENDIX E: Faculty Member Survey Introduction Letter 109

APPENDIX F: Faculty Member Demographics Survey 111

APPENDIX G: EQ-i Individual Summary Report and Key 113

APPENDIX H: OCDQ-HE-Partial Individual Summary Report and Key 123

$\begin{array}{ll}\text { CURRICULUM VITA } & 128\end{array}$ 


\section{List of Figures}

Figure

Page

Figure 1 This matrix illustrates variables which were examined by Research Question One.

Figure 2 This matrix illustrates variables which were examined by Research Question Two.

Figure 3 This matrix illustrates variables which were examined by Research

Figure 4 This figure indicates the WV State CTC population and distribution of chairs and faculty and survey return frequencies and rates. 


\section{List of Tables}

Table

Page

Table 1 Correlation Between Emotional Quotient and Organizational Climate 44

Table 2 Correlation Between the EQ Intrapersonal Category and OCDQ Subcategories 46

Table 3 Correlation Between the EQ Interpersonal Category and OCDQ Subcategories 47

Table 4 Correlation Between the EQ Stress Category and OCDQ Subcategories 48

Table 5 Correlation Between the EQ Adaptability Category and OCDQ Subcategories 49

Table 6 Correlation Between the EQ General Mood Category and OCDQ Subcategories 50

Table 7 Correlation Between EQ and Chair Age and Experience 51

Table 8 Chairpersons' EQ-i by Gender 52

Table 9 Correlation Between Organizational Climate and Chair Age and Experience 53

Table 10 Chairpersons' OCDQ-HE by Gender 54

Table 11 Correlation Between OCDQ-HE and Faculty Members' Age and Experience 55

Table 12 Faculty Members' OCDQ-HE by Gender $\quad 55$

Table 13 Distribution of Chairpersons' EQ-i Scores 57

Table 14 Distribution of Chairpersons' EQ-i Scores by Gender 57

Table 15 Distribution of Chairpersons' EQ-i Scores by Age 58

Table 16 Correlation Between Chairpersons' Age Groups and Emotional Quotient 59

Table 17 Distribution of Chairpersons' EQ-i Scores by Years of Experience as Chair 60

Table 18 Correlation Between Faculty Members' Age and Experience and OCDQ Subcategories $\quad 62$

Table 19 Distribution of Faculty Members' OCDQ-HE Scores by Age 63 


\section{Chapter 1}

Introduction

The academic department is the base unit and central building block of American universities and colleges. While academic departments fragment and divide the faculty of an institution of higher education, they also provide a useful structure for the day-to-day activities that shape faculty members' attitudes, behaviors, and performances (Seagren, Creswell, \& Wheeler, 1993).

As the leader of the academic department, the department chairperson presides over daily college affairs and acts as a buffer between faculty and administration, and they often function as mediators, communicators, and facilitators. According to Gillett-Karam (1999), an "institution's success parallels that of the chair's success, because without the chair's sense of timing, direction, skills, and leadership, the college stands to lose its cohesiveness, alignment, and representation" (p. 5).

Although upper-level administrators are responsible to various external constituencies, the department chair's attention must be focused internally on the day-to-day administration of campus activities. Upper-level administration is expected to declare the vision and mission of the college, but without coordination and cooperation between upper-level administrators and chairs who are aligned with students and faculty, the vision and mission of the college would not be well-grounded or representative (Gillett-Karam, 1999).

Department chairs are charged with creating a shared vision for their respective departments, and they are responsible for developing an 
organizational climate conducive to motivating and developing faculty members. In addition, department chairs should create a supportive communication climate that emphasizes listening skills, thus demonstrating their respect and empowerment of faculty members and students. According to Gillett-Karam (1999), "the chair is instrumental in motivating, evaluating, rewarding, and providing faculty development. When these efforts are deficient in an institution, the chair is responsible" (p. 7).

As leaders of academic departments, department chairs are required to motivate, evaluate, reward, and provide faculty development opportunities for their faculty members. The ability or inability of department chairs to perform these activities directly affects their faculty members' attitudes, behaviors, and performances, and it is the collective attitudes, behaviors, and performances of department faculty that define the organizational climate of the department.

George Litwin and Robert Stringer (1968) define organizational climate as "a set of measurable properties of the work environment based on the collective perceptions of the people who live and work in the environment, and (the collective perceptions) demonstrated (are known) to influence their behavior" ( $p$. 1). Many internal organizational characteristics influence the climate of an organization, and according to Hoy and Miskel (2001), "teachers' (faculty members') perceptions of the general work environment of the school; the formal organization, informal organization, personalities of the participants, and organizational leadership influence it (organizational climate)" (p. 189). 
As leaders of academic departments, chairpersons have great potential for developing a positive organizational climate in their respective departments. Lucas (1994) asserts, "the organizational climate exudes excitement when department leadership is strong, and it is the chair who creates the climate ( $p$. 45)." Department chairpersons have much to benefit by creating a positive organizational climate because the creation of a positive climate is critical to faculty retention, and the overall commitment to a department should increase when an open environment is present and faculty members believe they are making meaningful contributions (Donahue, 1986). In the aforementioned studies, it appears that it is necessary for department chairpersons to exercise interpersonal and relationship skills in order to create a positive organizational climate, and according to Goleman (1995), a person's collective interpersonal and relationship abilities equate to a larger construct known as emotional intelligence.

Goleman (1995) suggests "the art of relationships is, in large part, skill in managing the emotions in others, and the skills involved are the abilities that undergird popularity, leadership, and interpersonal effectiveness" (p.43). People who excel in these skills do well at anything that relies on interacting smoothly with others; they are social stars (Goleman, 1995). According to Goleman (1998), "for star performance in all jobs, in every field, emotional competence is twice as important as purely cognitive abilities, and for success at the highest levels, in leadership positions, emotional competence (intelligence) accounts for virtually the entire advantage" (p. 34). 
In more recent research, Goleman, Boyatzis, and McKee (2002) assert that people pay close attention to a leader's emotional states by watching how expressively the leader's face, voice, and gestures convey their feelings. Even subtle expressions of emotion can have great impact, and when leaders are more open and express their own enthusiasm, the more others will feel that same contagious passion. The greater a leader's skill at transmitting emotions, the more forcefully emotions will spread (Goleman, Boyatzis, and McKee, 2002).

The theory of emotional intelligence has emerged during the past twenty years (Bar-On, 1997). Although there is an abundance of research on emotional intelligence (Wechsler, 1940; Maslow, 1950; Maslow, 1954; Leeper, 1948; BarOn, 1988; Goleman, 1995; Bar-On, 1997; Cooper \& Sawaf, 1997; Goleman, 1998; Weisinger, 1998; Feldman, 1999; Cherniss \& Adler, 2000; Boyatzis, Goleman, \& Rhee, 2000; Goleman, Boyatzis, \& McKee, 2001; and Goleman, Boyatzis, \& McKee, 2002) its relationship to leadership (Cherniss \& Adler, 2000; Cooper \& Sawaf, 1997; Feldman, 1999; Goleman, 1998; and Goleman, Boyatzis, \& McKee, 2002) and its impact on organizational climate in corporations (Cherniss \& Goleman, 2001; Goleman, Boyatzis, \& McKee, 2001; Goleman, Boyatzis, \& McKee, 2002; Weisinger, 1998), little research exists on emotional intelligence and its relationship to higher education leadership and organizational climate (Astin \& Astin, 2000; Hopper, 2005).

\section{Statement of the Problem}

Review of available literature indicates that emotional intelligence and its relationship to academic department leadership and organizational climate 
warrants further investigation. The purpose of this study is to examine the relationship between the emotional intelligence competencies of department chairs in the West Virginia state community college system and their faculty members' perceptions of organizational climate. The following questions will be answered in this study:

1. What relationship exists, if any, between the chairperson's levels of emotional intelligence competencies and organizational climate as perceived by faculty members in the department or division?

2. What relationship exists, if any, between age, gender, years of experience as a chairperson, years of experience as chairperson in the current department or division, and the emotional intelligence competencies of chairpersons and organizational climate as perceived by faculty members in the departments or divisions?

3. What relationship exists, if any, between age, gender, years of teaching experience as a faculty member in the current department or division, and organizational climate as perceived by faculty members in the departments or divisions?

\section{Justification/Need for the Study}

Gulick and Urwick (1937) identify the following seven tasks required of administrators: planning, organizing, staffing, directing, coordinating, reporting, and budgeting (POSDCoRB). Understanding the relationship of the emotional intelligence competencies of department or division chairpersons to faculty members' perceptions of organizational climate may assist chairpersons in 
performing these seven administrative functions more effectively. Data from this study should be particularly beneficial in relation to the organizing, directing, and coordinating functions. If recent research on the impact of emotional competencies on leadership skills holds true for leaders in education, this information could be beneficial to higher education institutions in identifying potential administrators, weaknesses in skills in practicing administrators, and areas to address in professional development of aspiring and current administrators.

\section{Limitations of Study}

1. Data in this study will be provided by chairpersons and faculty members in the West Virginia State (Public) Community and Technical College system and may not generalize to chairpersons and faculty members in other public higher education institutions in the West Virginia State system or to public institutions of higher education in other states across the nation.

2. The study will use self-reported assessment surveys and is limited to the accuracy of the participants' responses.

3. Data in this study will be collected using a single instrument for each variable.

4. This study will be limited by the reliability and validity of the instruments utilized.

\section{Definition of Terms}

For the purposes of this study, the following operational definitions are used:

1. Gender - the gender (male or female) reported by the chairperson on the demographic component of the Emotional Quotient Inventory or the gender 
(male or female) of the faculty member reported on the demographic component of the organizational climate description questionnaire for academic departments in colleges and universities (OCDQ-HE, Partial).

2. Emotional Intelligence Competencies - the chairperson's total emotional quotient score, the chairperson's five emotional quotient composite scale scores, and the chairperson's fifteen emotional quotient subscale scores on the Bar-On Emotional Quotient Inventory (EQ-i) (Appendix A).

3. Organizational Climate - the total mean score of the four organizational climate factors of the OCDQ-HE-Partial and the individual score totals of the four organizational climate factors (Appendix B).

4. West Virginia State Community and Technical College - A West Virginia State (public) associate degree granting college with a Carnegie classification of class 40 or a West Virginia State (public) associate degree granting college offering select baccalaureate degrees with a Carnegie classification of class 33. There are ten community and technical colleges in the West Virginia State Community and Technical College System which include Blue Ridge (formerly Shepherd) Community and Technical College, Eastern Community and Technical College, Marshall Community and Technical College, New River Community and Technical College, Northern Community and Technical College, Pierpont (formerly Fairmont State) Community and Technical College, Southern Community and Technical College, West Virginia Institute of Technology Community and Technical College, West Virginia State Community and Technical College, and West Virginia University at 
Parkersburg Community and Technical College. Of the ten community and technical colleges in the West Virginia State (Public) System, Eastern and New River Community and Technical Colleges did not have department or division chairpersons as part of their organizational structures, and those institutions were not included in this study.

5. Chairpersons - A person in charge of an academic unit (departments or divisions) in the West Virginia State (Public) Community and Technical College system that are participating in this study.

6. Faculty - all instructors or professors (assistant, associate, or full) teaching full-time in the West Virginia State (Public) Community and Technical Colleges of the chairpersons that are participating in this study.

7. Years of Experience - the number of self-reported years a chairperson has served as an academic unit or division chair or the number of self-reported years a faculty member has served as an instructor or professor in an institution of higher education.

8. Years of Experience in a Department or Division- the number of self-reported years a chairperson has served as an academic unit or division chair of a department or division or the number of self-reported years a faculty member has served as an instructor or professor in a department or division. 


\section{Chapter 2}

Review of Literature

\section{Leadership}

The study of leadership began early in the twentieth century with trait theory, which suggests that leaders possess unique physical and psychological characteristics (specific traits) that predispose them to positions of influence (Hackman \& Johnson, 2000). However, in 1948, Ralph Stogdill published a review of 124 studies that examined traits and personal factors related to leadership, which uncovered a number of inconsistent findings (Stogdill, 1948). Stogdill (1948) concluded:

A person does not become a leader by virtue of the possession of some combination of traits, but the pattern of personal characteristics of the leader must bear some relevant relationship to the characteristics, activities, and goals of the followers." (p. 64)

As a result of Stogdill's research, a shift in the emphasis from the personal characteristics of leaders to their behaviors as leaders began. As the traits approach became less credible as an explanation of leadership behavior (late 1940s to the late 1960s), many researchers began to pursue situational explanations of leadership in the early 1970 s.

Situational explanations of leadership or situational approaches, often called contingency approaches, which emphasize the importance of situational factors and the nature of the external environment, assume that leadership behavior is contingent upon variations in the situation. The four most commonly studied 
situational leadership approaches are Fiedler's contingency model of leadership, path-goal theory, Hersey and Blanchard's situational leadership theory, and leader-member exchange theory influence (Hackman \& Johnson, 2000). An additional approach to studying leadership, transformational leadership, was initiated by James Burns in the late 1970s.

Burns (1978) compared traditional leadership, which he labeled as "transactional," with a more complex and potent type of leadership that he called transforming. In later studies on transformational leadership in the 1980s and 1990s, researchers (Bennis \& Nanus, 1985; Kouzes \& Posner, 1995; and Peters \& Waterman, 1982) identified characteristics of transformational leaders that were remarkably similar. Transformational leaders were determined to be creative, interactive, visionary, empowering, and passionate (Hackman, Johnson, 2000). Transformational leaders often define the need for change, create a vision, gain follower commitment to the vision, and inspire their followers to achieve established goals. Transformational leaders can convert followers into leaders themselves, and those leadership characteristics often filter throughout transformed groups and organizations.

Transformational leaders are passionately committed to their work, their jobs, their followers, and their organizations. The passion and personal enthusiasm of a transformational leader is contagious as it motivates followers to perform to their highest level, instilling in them commitment to their work, job, and organization. This characteristic of transformational leadership can be considered 
part of a newer approach to the study of leadership, which is called the symbolic approach.

Cultural and symbolic theories represent a paradigm shift in leadership studies. In symbolic leadership, leaders construct and maintain systems of shared meanings, paradigms, and shared languages and cultures by sustaining rituals, symbols, and myths that create a unifying system of belief for the institution (Bensimon, 1989; Bolman \& Deal, 1997). With symbolic leadership, leadership is not viewed as an objective act in which leaders display traits or behaviors to influence followers, but rather as a subjective act where leaders construct a reality that reflects desired ends and is compatible with followers' beliefs.

Some of the same principles of transformational and symbolic leadership applies to emotional intelligence (EI), but with $\mathrm{El}$, more emphasis is placed on ethics, morals, values, integrity, collaborative skills, and the influence of the leader on the climate or mood of the organization (Goleman, Boyatzis, \& McKee, 2002).

\section{Emotional Intelligence}

According to Bar-On (1997), the theory of emotional intelligence has its origins in the work of Wechsler (1940), Maslow (1950, 1954), and Leeper (1948). Subsequent research by Bar-On in 1988, which was based on the work of these researchers, led to his use of the term emotional quotient (EQ).

In the 1980's, the scientific studies of emotion and the development of brainimaging technologies allowed researchers to see for the first time in human 
history how the brain operates while we think and feel, and imagine and dream (Goleman, 1995). The studies permitted researchers to map with some precision the human heart and psyche, but the mapping offered a challenge to those who subscribed to the narrow view of intelligence. They argued "IQ is a genetic given that cannot be changed by life experience, and that our destiny in life is largely fixed by these aptitudes" (Goleman, 1995, p. xi). Goleman (1995; 1998) asserted: What factors are at play ... when people of high IQ flounder and those of modest IQ do surprisingly well? I would argue that the difference quite often lies in the abilities called here emotional intelligence, which includes self-control, zeal and persistence, and the ability to motivate oneself. ( $p$. xii)

These skills (emotional intelligence), can be taught to children, giving them a better chance to use whatever intellectual potential that heredity may have given them (Goleman, 1995, 1998; Bar-On, 1997; Weisinger, 1998).

In the mid-1990's, the theory of emotional intelligence and its relationship to leadership skills began to emerge as a theory of performance that could be used to predict personal effectiveness in leadership (Goleman, 1995; Goleman, 1998; Goleman, Boyatzis \& McKee, 2001; Feldman, 1999).

In the late 1990's, Cooper and Sawaf (1997) announced the beginning stages of the next business revolution which began with a series of studies on emotional intelligence indicating that people who are intellectually the brightest are often not the most successful, either in business or their personal lives. They asserted that "modern science is proving every day that it is emotional intelligence, not IQ or 
raw brain power alone, that underpins many of the best decisions, the most dynamic and profitable organizations, and the most satisfying and successful lives" (Cooper \& Sawaf, 1997, p. xii). Cooper and Sawaf (1997) continued by stating that the "emerging research suggests that a technically proficient executive or professional with a high $\mathrm{EQ}$ (emotional quotient) is someone who picks up - more readily, more deftly, and more quickly than others the subtleties of the work environment that can influence organizational effectiveness" (p. xi). Cooper and Sawaf (1997) defined emotional intelligence as "the ability to sense, understand, and effectively apply the power and acumen of emotions as a source of human energy, information, connection, and influence" (p. xiii). And, they asserted that the application of emotional intelligence can make the difference in critical success factors in a career or organization including such factors as decision-making, leadership, strategic and technical breakthroughs, open and honest communication, trusting relationships and teamwork, customer loyalty, and creativity and innovation (Cooper \& Sawaf, 1997).

In 1998, Goleman (1998) reported a disturbing piece of data from a survey of parents and teachers that showed that the present generation of children to be more emotionally troubled than the last. According to the report, children are growing more lonely and depressed, more angry and unruly, more nervous and prone to worry, and more impulsive and aggressive, and Goldman (1998) noted a steady worsening of children's emotional intelligence that spanned all economic groups. Cherniss and Adler (2000) maintained that "this data means that the generation of workers now entering the American workplace is less likely 
than previous generations to possess the social and emotional qualities that are essential for effective performance" (p.7).

During the 1990's, a survey of American employers revealed that more than 50 percent of their employees lacked the motivation to keep learning and improving in their jobs, and when asked what they are looking for in entry-level workers, the employers said that specific technical skills are less important than the ability to learn on the job (Goleman, 1998). "After that (ability to learn on the job), the employers listed:

- Listening and oral communication

- Adaptability and creative responses to setbacks and obstacles

- Personal management, confidence, motivation to work toward goals, a sense of wanting to develop one's career and take pride in accomplishments

- Group and interpersonal effectiveness, cooperation and teamwork, skills at negotiating disagreements

- Effectiveness in the organization, wanting to make a contribution, and leadership potential. (Goleman, 1998, pp. 12-13)

The entry-level employee skills valued by the employers are all components of emotional intelligence called emotional competencies. Cherniss and Adler (2000) contend that emotional competencies are learned and not innate and they can include a person's attitudes and beliefs as well as skills and abilities.

When considering emotional intelligence in the workplace, Weisinger (1998) stated that "the lack of emotional intelligence undermines both an individual's and 
a company's growth and success, and conversely ... the use of emotional intelligence leads to productive outcomes at both the individual and the organizational levels" (p. xviii).

Feldman (1999) and Cherniss and Adler (2000) warned that organizational structures are changing rapidly in all sectors: private, non-profit, and government due to the impact of technology, globalization, and changing (flattening, decentralizing) organizational structures. Feldman (1999) stated that "the need for emotionally intelligent leadership in organizations is greater today than ever" ( $p$. 4).

Goleman (1995) identified emotional intelligence as the ability to identify and understand one's own emotional reactions and those of others, and he proposed that there were five dimensions of emotional intelligence. The five dimensions of emotional intelligence with twenty-five competencies were later reduced to four dimensions with nineteen competencies by him and his colleagues (Boyatzis, Goleman, \& Rhee, 2000). These dimensions have been identified by Boyatzis, Goleman, and Rhee (2000) as:

- Self-awareness - This dimension consists of knowing one's internal states, preferences, resources, and intuitions. This dimension contains the competencies of emotional self-awareness, accurate self-assessment, and self-confidence.

- Self-management - This dimension involves the management of one's internal states, impulses, and resources to facilitate reaching goals. This 
dimension contains the competencies of self-control, trustworthiness and conscientiousness, adaptability, achievement orientation, and initiative.

- Social Awareness - This dimension is comprised of being aware of others' feelings, needs, and concerns. This dimension contains the competencies of empathy, organizational awareness, and service orientation, and developing others.

- Social Skills -This dimension involves adeptness at inducing desirable responses in others. This dimension contains the competencies of leadership, communication, influence, change catalyst, conflict management, building bonds, teamwork and collaboration and developing others.

Cherniss and Adler (2000) developed a comprehensive framework based on Goleman's (1995) model, which identifies four similar dimensions of emotional intelligence and nineteen associated competencies. They suggest that these competencies are essential to leading emotionally intelligent organizations and cite several research studies to support their beliefs (Cherniss \& Adler, 2000).

The emotional intelligence model developed by Bar-On (1988) includes the same basic components found in the Boyatzis, Goleman, and Rhee (2000) model and the Cherniss and Adler (2000) model, but he categorizes them in a slightly different way. The fifteen competencies identified by Bar-On (1988) are the basis for the development of the BarOn Emotional Quotient Inventory (EQ-i), the first empirically tested instrument developed for the assessment of emotional intelligence (Bar- On, 1997). Bar-On (1997) identifies the five categories of 
emotional intelligence and associated competencies measured by the BarOn

Emotional Quotient Inventory (EQ-i) as:

- Intrapersonal EQ competencies - self-regard, emotional and self-

awareness, assertiveness, independence, and self-actualization

- Interpersonal EQ competencies - empathy, social responsibility, and interpersonal relationship

- Stress Management EQ competencies - stress tolerance and impulse control

- Adaptability EQ competencies - reality testing, flexibility, and problem solving

- General Mood EQ competencies - optimism and happiness Emotional Intelligence, Age, and Gender According to Bar-On (1997), the results for age and gender effects on the BarOn Emotional Quotient Inventory (EQ-i) revealed no significant differences between males and females regarding overall emotional and social competence. However, age results indicated that the older groups scored significantly higher than the younger groups on most of the EQ-i scale scores with respondents in their late forties and early fifties receiving the highest mean score (Bar-On, 1997). Bar-On (1997) and Goleman (1998) suggest that these results indicate that emotional and social intelligence increase with age. Emotional Intelligence and Leadership

When considering the relationship between leadership and emotional intelligence, Cooper and Sawaf (1997) maintain we are largely in the dark when it 
comes to learning how to become not only exceptional managers and leaders, but also notable men and women. One of the central missing pieces of the puzzle is emotional intelligence (Cooper \& Sawaf, 1997). With Goleman's (1998) analyses of a myriad of jobs, he found that emotional competence makes up about two thirds of the ingredients of a star's (leader's) performance in general, but for outstanding leaders, emotional competencies - as opposed to technical or cognitive cues - make up 80 to 90 percent of those listed by companies themselves as crucial for success.

According to Goleman (1998), leaders who demonstrate superior emotional competencies inspire and guide individuals and groups by articulating and arousing enthusiasm for a shared vision and mission; step forward to lead as needed regardless of position; guide the performance of others while holding them accountable; and lead by example. Feldman (1999), asserts "if you bring (practice) emotionally intelligent leadership into your organization, colleagues will appreciate your contribution; invite its development in others, and you will help create a high-performing organization that is able to change and lead into the future" (p. 74). Cherniss and Adler (2000) maintain that;

Once an individual becomes an executive or manager, what distinguishes that person's performance from another's are self-confidence, self-control, and the ability to motivate others. In other words, having an IQ of 130 instead of 120 will not make that much difference for a manager but having a bit more self-confidence or being a little more skilled in handling one's own feelings and those of others can make a big difference. (p. 5) 
Many studies related to the emotional intelligence of corporate leaders have been reviewed by Cherniss \& Adler (2000), Cooper \& Sawaf (1997), Goleman (1998), and Goleman, Boyatzis, \& McKee (2002), and the results of those studies indicate a strong relationship between emotional intelligence and high performance and/or emotional intelligence and effective leadership. Emotional Intelligence and Higher Education Leadership

When considering the relationship between intelligence emotional intelligence and higher education leadership, Astin \& Astin (2000) state that in the classroom, college faculty continue to emphasize the acquisition of knowledge in the traditional disciplinary fields and the development of writing, quantitative, and critical thinking skills. However, they give relatively little attention to the development of those personal qualities that are most likely to be crucial to effective leadership, which are self-understanding, listening skills, empathy, honesty, integrity, and the ability to work collaboratively. Astin \& Astin ascertain that most of these qualities exemplify aspects of what Daniel Goleman (1997) would call "emotional intelligence," but one seldom hears mention of these qualities or of leadership or leadership skills in faculty discussions of curricular reform, even though goals such as producing future leaders are often found in the catalogs and mission statements of colleges and universities. The results of a recent study by Hopper (2005) demonstrated that the traits associated with Goleman's (1998) framework of emotional intelligence are relevant to a discussion of the best qualifications for (college) library directors. 


\section{Emotional Intelligence and Organizational Climate}

Several research studies on leadership show that the emotional intelligence of a group's leader has a powerful impact on the group's climate and effectiveness (Cherniss \& Goleman 2001; Goleman, Boyatzis, \& McKee, 2001; Goleman, Boyatzis, \& McKee, 2002; Weisinger, 1998). Cherniss and Goleman (2001) indicate that "the evidence suggests that emotionally intelligent leadership is key to creating a working climate that nurtures employees and encourages them to give their best ... that enthusiasm, in turn, pays off in improved business performance" (p. 40). The relationship between El strengths in a leader and performance of the unit (organization) led appears to be mediated by the climate the leader creates (Cherniss \& Goleman, 2001). Goleman, Boyatzis, and McKee (2001) contend that their research shows that a leader who is optimistic, positive, friendly, and supportive creates an organization in which the members exhibit those same characteristics and perform at high levels. On the other hand, leaders who have toxic personalities create organizations in which the members are negative, pessimistic, emotionally unhealthy, and perform below capacity (Goleman, Boyatzis, \& McKee, 2001). According to Goleman, Boyatzis, and McKee (2002), "Roughly 50 to 70 percent of how employees perceive their organization's climate can be traced to the actions of one person: the leader" ( $p$. 18).

\section{Organizational Climate - Definition and Description}

Hoy and Miskell (2001) define school (organizational) climate for elementary, middle, and secondary schools as "a broad term that refers to teachers' 
perceptions of the general work environment (internal characteristics) of the school; the formal organization, informal organization, personalities of participants, and the organizational leadership that influences it" (p. 189). Hoy and Miskell (2001) assert that "school climate is a relatively enduring quality of the school environment that is experienced by participants, affects their behavior, and is based on their collective perceptions of behavior in schools" (p. 190). The definition of organizational climate as a set of internal characteristics is similar in some respects to early descriptions of personality; thus the climate of a school may be roughly be conceived as the personality of a school (Hoy \& Miskell, 2001).

Since the atmosphere of a school has a major impact on organizational behavior, and because administrators can have a significant influence on the development of the "personality" of the school, it is important to describe and analyze school climates. In 1962, when Halpin and Croft (1962) began mapping the organizational climate of elementary schools, they observed that: 1) Schools differ markedly in their feel, 2) The concept of morale did not provide an index of this feel, 3) "Ideal" principals who are assigned to schools where improvement is needed are immobilized by the faculty, and 4) The topic of organizational climate was generating interest.

The approach they used involved developing a descriptive questionnaire to identify important aspects of teacher-teacher and teacher-principle interactions. Initially, nearly 1,000 items were composed, which were designed to answer the basic question: To what extent is this true of your school? From this original bank 
of items they developed a final set of 64 items called the Organizational Climate Description Questionnaire (OCDQ) (Hoy \& Miskell, 2001).

The OCDQ measures six dimensions of organizational climate identified as: supportive behavior, directive behavior, restrictive behavior, collegial behavior, intimate behavior, and disengaged behavior. Within the last decade, three new and simplified versions of the OCDQ were formulated for elementary (OCDQRE), middle (OCDQ-RM), and secondary schools (OCDQ-RS) (Hoy \& Miskell, 2001).

The OCDQ identifies four different climate profile types: open, engaged, disengaged, and closed. In an open school climate cooperation and respect exist within the faculty and between the faculty and the principal. In an engaged school climate, the principal is ineffective in controlling the organization, but faculty members are high in professional performance. In a disengaged school climate, the principle is open, concerned, and supportive, but faculty members do not accept, respect, or like the principal. In a closed school climate cooperation and respect do not exist within the faculty or between the faculty and the principal (Hoy \& Miskell, 2001).

Hoy and Miskell (2001) maintain that " the three versions of the OCDQ for elementary, middle, and secondary schools are useful devices for general charting of school climate in terms of teacher to teacher and teacher to principal relationships" (p. 196). The subtests of each instrument appear to be valid and reliable measures of important aspects of school climate, and they can provide 
climate profiles that can be used for research, evaluation, in-service, or selfanalysis (Hoy \& Miskell, 2001).

In 1972, Borrevik (1972) identified the need for an instrument similar to Halpin and Croft's OCDQ to measure organizational climate at the higher education level. As a result of Borrevik's study, the OCDQ-HE for higher education was developed to measure the organizational climate that surrounds academic departments in colleges and universities (Borrevik, 1972). The OCDQ-HE consists of fifty items and measures six dimensions (subtests) of organizational climate: consideration, intimacy, disengagement, production emphasis, student involvement, and detachment (Borrevik, 1972). Borrevik (1972) defines the six dimensions as follows:

Consideration: The chairperson's behavior is friendly and open, and he or she listens and is open to faculty member suggestions. Praise is given genuinely and frequently, and criticism is handled constructively.

Intimacy: Faculty member behavior reflects a cohesive and strong network of social support. Faculty members know each other well, are close personal friends, and socialize together regularly.

Disengagement: Fractionalization exists within the faculty and professional activities lack focus and meaning. Faculty members are simply putting in time and are nonproductive in group efforts and team building, and they have no common goal orientation. Their behavior is often negative and critical of their colleagues and the institution. 
Production Emphasis: The chairperson closely supervises the faculty and applies pressure for productive output. The chairperson places the department's welfare above the welfare of individual faculty members.

Student Involvement: Characterized by students' influence over the group. It involves the recognition of students as a group, the behavior they exhibit in trying to influence the faculty and the way they respond to ideas and events from the department (division).

Detachment: Defined in terms of group behavior which includes both students and faculty, and it is characterized by formality and impersonal behavior.

Borrevik's (1972) research confirmed that the OCDQ-HE is a satisfactory instrument to assess the organizational climate of academic departments.

\section{Summary}

A highly effective division chairperson will have all the positive traits of a transformational leader: creative, interactive, visionary, empowering, and passionate as Hackman \& Johnson (2000) describe coupled with high emotional intelligence, which will allow him or her "the ability to sense, understand, and effectively apply the power and acumen of emotions as a source of human energy, information, connection, and influence" as Cooper and Sawaf (1997) describe (p. xiii).

That ideal chairperson will be able to create and maintain a positive organizational climate where information sharing, trust, healthy risk-taking, and learning flourish, and he or she will be able to define the need for change, create 
a vision, gain follower commitment to the vision, and inspire followers to achieve established goals.

Since that ideal chairperson most likely does not exist, it becomes necessary to assess our organizations utilizing the emotional quotient inventory (EQ-I) instrument to determine the emotional intelligence competencies of our department chairpersons, and the organizational climate description questionnaire for higher education (OCDQ-HE) to determine the organizational climate of our institutions. Data from the assessment would identify deficiencies where improvement would likely increase organizational effectiveness. The present study investigated the relationship between emotional intelligence competencies of department chairpersons and faculty members' perceptions of organizational climate. 


\section{Chapter 3}

Research Methods and Procedures

The purpose of this chapter is to provide a description of the population, the procedures and instruments that were used to gather data, and the statistical methods that were utilized to analyze that data. In this study, data were gathered to determine the relationship between the emotional intelligence competencies of department (division) chairs in the West Virginia State community college system and their faculty members' perceptions of organizational climate.

\section{Population}

The population of this study was all of the department (division) chairs employed by the West Virginia State community college system during the 20062007 academic year. There are ten community and technical colleges in the West Virginia State Community and Technical College System which include 1) Blue Ridge (formerly Shepherd) Community and Technical College, 2) Eastern Community and Technical College, 3) Marshall Community and Technical College, 4) New River Community and Technical College, 5) Northern Community and Technical College, 6) Pierpont (formerly Fairmont State) Community and Technical College, 7) Southern Community and Technical College, 8) West Virginia Institute of Technology Community and Technical College, 9) West Virginia State Community and Technical College, and 10) West Virginia University at Parkersburg Community and Technical College. Of the ten community and technical colleges in the West Virginia State (Public) System, Eastern and New River Community and Technical Colleges do not have 
department or division chairpersons as part of their organizational structures, and as such, those institutions were not included in this study. Of the remaining eight West Virginia State Community and Technical Colleges, 40 department (division) chairs were identified. All 40 department (division) chairs were surveyed using the Bar-On Emotional Quotient Inventory (EQ-i) (Appendix A). The population of faculty members in the eight remaining West Virginia State community colleges numbers 326 . All 326 faculty members were surveyed using the organizational climate description questionnaire for academic departments of colleges and universities (OCDQ-HE-Partial) (Appendix B). Faculty members were asked to complete the OCDQ-HE-Partial to assess their perceptions of organizational climate, and faculty members' responses on the OCDQ-HE-Partial were matched to their department chair's responses on the EQ-i. The population and distribution of chairpersons and faculty members in the West Virginia State Community and Technical College System and the surveys' return frequencies and rates are indicated by Figure 4 in chapter four on page 41 .

Research Questions and Conceptual Models (Matrices)

1. What relationship exists, if any, between the chairperson's levels of emotional intelligence competencies and organizational climate as perceived by faculty members in the departments or divisions? The researcher examined overall EQ-I scores versus overall OCDQ-HE scores and EQ composite category scores (Intrapersonal, Interpersonal, Stress Management, Adaptability, General Mood) versus OCDQ-HE category scores (Consideration, Intimacy, 
Disengagement, Production Emphasis) using Pearson Product Moment

Correlation tests for a total of 21 comparisons (Figure 1).

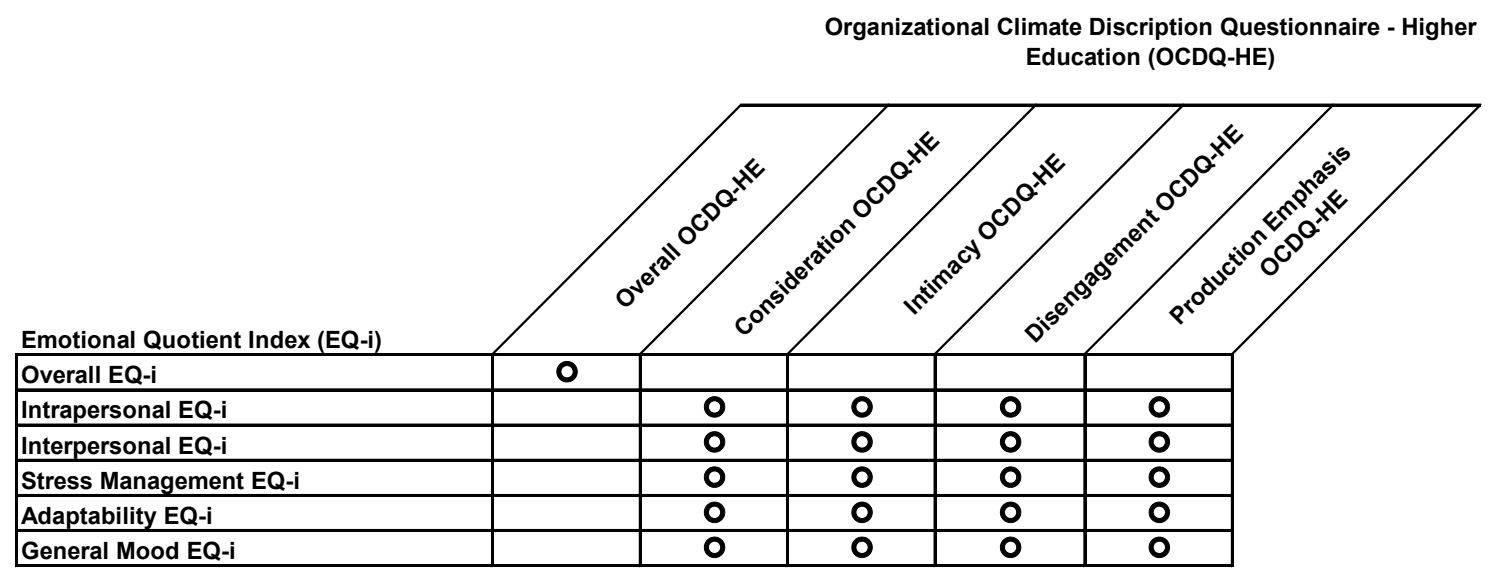

Figure 1: This matrix illustrates variables which were examined by Research Question One.

2. What relationship exists, if any, between (a) age, gender, years of experience as a chairperson, years of experience as chairperson in the current department or division, and the (b) emotional intelligence competencies of chairpersons and (c) organizational climate as perceived by faculty members in those departments or divisions? The researcher studied department chair demographic information versus their EQI scores and their faculty members' overall OCDQ-HE scores using Pearson product moment correlation tests for ratio scale data and chi square tests for nominal data. The following areas were examined for a total of eight comparisons: age, gender, years of experience as a chairperson, and experience as chairperson in the current department or division (Figure 2). 


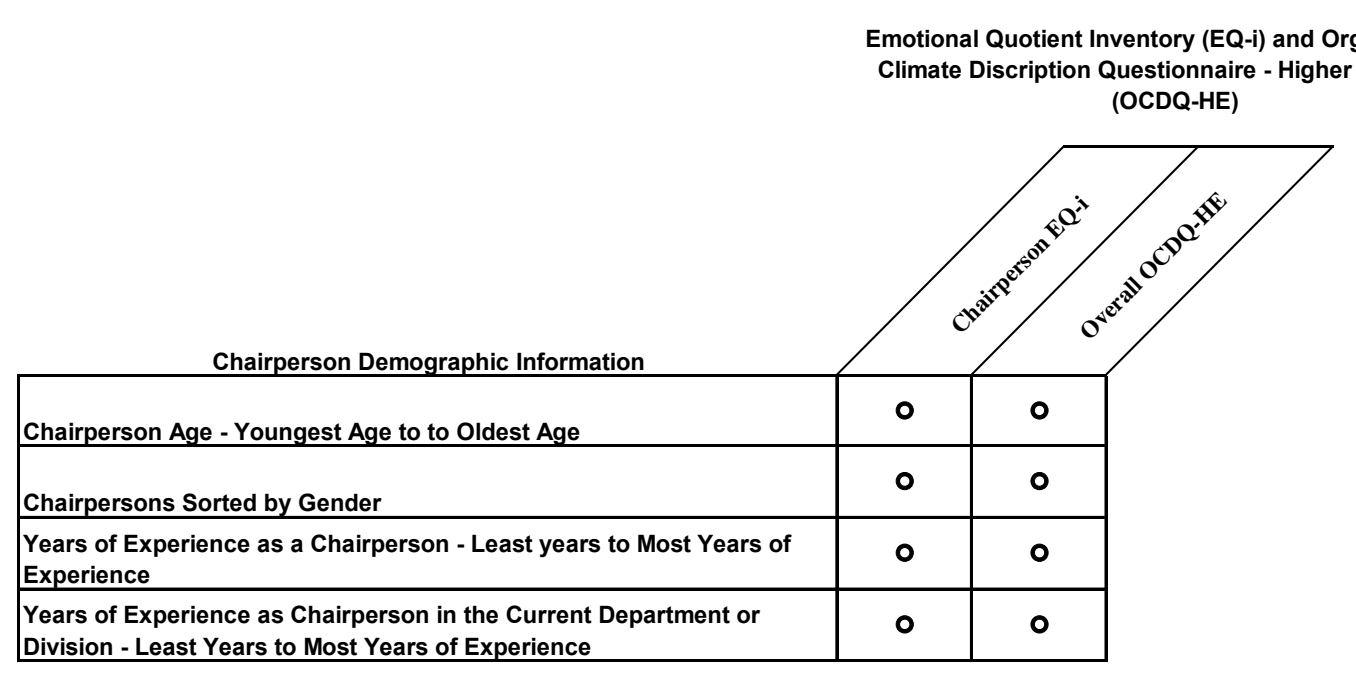

Figure 2: This matrix illustrates variables which were examined by Research Question Two.

3. What relationship exists, if any, between age, gender, years of teaching experience as a faculty member in the current department or division, and organizational climate as perceived by faculty members in those departments or divisions? The researcher examined faculty demographic information versus overall OCDQ-HE scores using Pearson Product Moment Correlation tests for ratio scale data and chi square tests for nominal data. The following areas were examined for a total of three comparisons: age, gender, and years of teaching experience as a faculty member in the current department or division (Figure 3). 


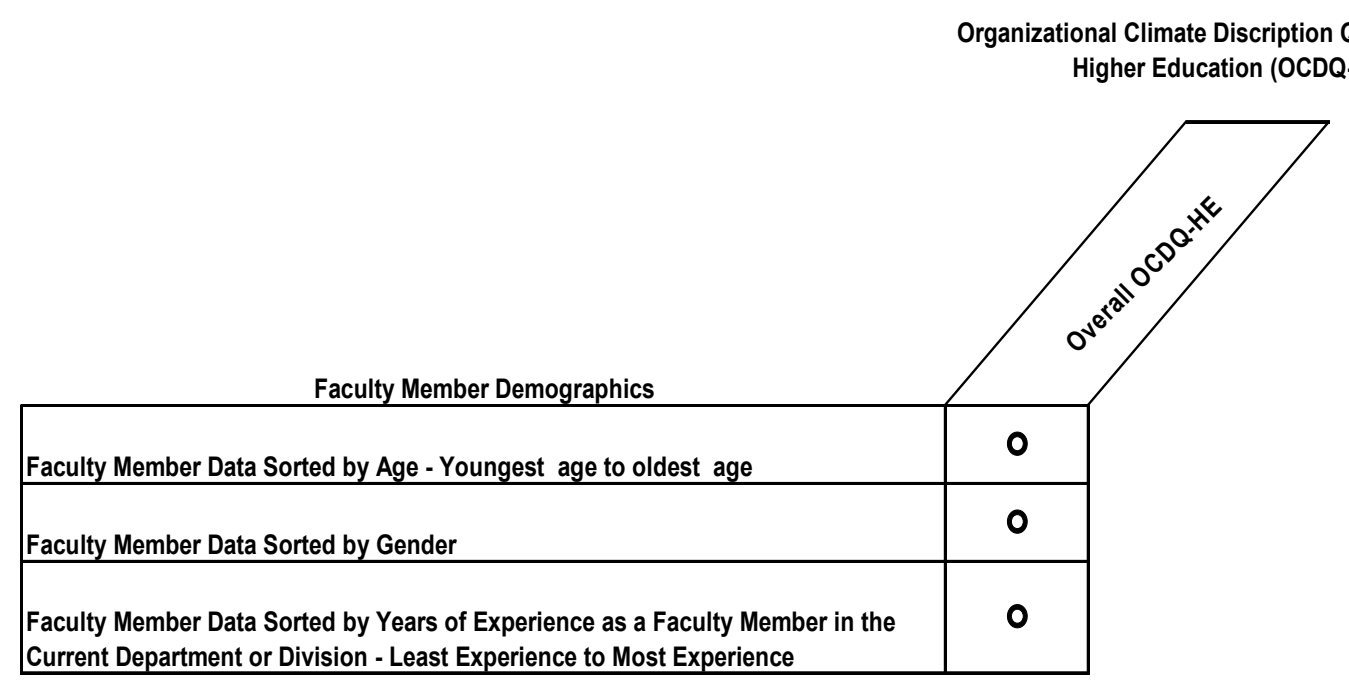

Figure 3: This matrix illustrates variables which were examined by Research Question Three.

\section{Measuring Emotional Intelligence Competencies}

This researcher used the Bar-On Emotional Quotient Inventory (EQ-i), which was developed by Bar-On (1997), to assess emotional intelligence competencies of department chairs (Appendix A). Bar-On (1997) describes the EQ-i as a selfreport assessment of one's emotional competencies consisting of 133 "brief items." According to Bar-On (1997), it takes about 30 to 40 minutes to complete the $E Q-i$.

EQ-i assessment provides four validity scale scores, a total EQ score, five composite scale scores, and 15 EQ sub-scale scores. Raw EQ-i scores are converted into standard scores based on a mean of 100 with a standard deviation of 15 (Bar-On, 1997). In addition, an inconsistency index, and positive and negative impression scales are calculated (Bar-On, 1997). Bar-On (1997) has incorporated a correction factor to adjust scores for overly positive or overly 
negative self-presentation. According to Bar-On (1997), this procedure may lead to more accurate scores for respondents who attempt to manipulate results.

Bar-On (1997) reports that the EQ-i was normed on a large and representative sample of the North American population that included nearly $4,000(N=3,831)$ participants from the United States and Canada. In addition, the normative sample was very diverse regarding age, socioeconomic, educational, and occupational/professional breakdown, and it was geographically representative of North America (Bar-On, 1997).

The EQ-i has an average internal consistency coefficient (Cronbach alpha) of 0.76 and average test-retest coefficients of 0.85 and 0.75 for one and four month time periods, respectively for the South African sample (Bar-On, 1997). According to Bar-On (1997), nine types of validity studies have been conducted on the EQ-i over the past 17 years. These validity studies include content, face, factor, construct, convergent, divergent, criterion-group, discriminate, and predictive validity (Bar-On, 1997). Results from these validation studies are summarized in over 60 pages in Bar-On's technical manual for the EQ-i (Bar-On, 1997).

\section{Measuring Organizational Climate}

Faculty members' perception of organizational climate was assessed by using the organizational climate description questionnaire for academic departments of colleges and universities (OCDQ-HE) developed by Berge Borrevik in 1972 (Appendix B). Borrevik (1972) identified the need for an instrument similar to Halpin and Croft's OCDQ to measure organizational climate at the higher 
education level. As a result of Borrevik's study, the OCDQ-HE for higher education was developed to measure the organizational climate that surrounds academic departments in colleges and universities (Borrevik, 1972). The OCDQHE consists of 50 items and measures six dimensions (subtests) of organizational climate: consideration, intimacy, disengagement, production emphasis, student involvement, and detachment (Borrevik, 1972).

Since the effect of student involvement on organizational climate was not explored in this study, the student involvement and detachment subtests were removed from the OCDQ-HE. The OCDQ-HE-Partial was administered to faculty members, which consists of the consideration, intimacy, disengagement, and production emphasis subtests.

The OCDQ-HE Partial questionnaire has a total of 42 questions with 21 positive and 21 negative organizational climate questions. The consideration (positive climate) subtest consists of 12 questions; the intimacy (positive climate) consists of 9 questions; the disengagement (negative climate) consists of 11 questions; and the production emphasis (negative climate) subtest consists of 10 questions. Respondents were asked to answer each question using the following five descriptor Likert scale: 1 - Almost never occurs, 2 - Infrequently occurs, 3 Approximately equal in occurrence and non-occurrence, 4 - Frequently occurs, and 5 - Almost always occurs.

The results of the OCDQ-HE-Partial surveys categorized departments or divisions as having either positive (open) or negative (closed) organizational 
climates. Departments or divisions were ranked on a continuum from -84 to 84 with the following six categories of organizational climate.

- Highly positive organizational climate: Score of 57 to 84

- Moderately positive organizational climate: Score of 29 to 56

- Slightly positive organizational climate: Score of 0 to 28

- Slightly negative organizational climate: Score of -28 to 0

- Moderately negative organizational climate: Score of -56 to -29

- Highly negative organizational climate: Score of -84 to -57

Borrevik (1972) reported that analysis of the domains identified by the six subtests of the OCDQ-HE revealed that four of the six domains (consideration, intimacy, disengagement, and production emphasis) closely resemble subtests established by the original OCDQ developed by Halpin and Croft.

Lewis (1991) reported Cronbach alphas for the four OCDQ-HE subset climate domains as being 0.93 for consideration, 0.84 for intimacy, 0.68 for disengagement, and 0.71 for production emphasis. Factor analysis, using varimax rotation, established construct validity (Lewis, 1991). The results of Borrevik's (1972) and Lewis' (1991) research studies validate the OCDQ-HE as a satisfactory instrument to assess the organizational climate of academic departments.

A self-report questionnaire, the Emotional Quotient Inventory (EQ-i), was administered to all of the department (division) chairs employed by the West Virginia State community college system during the 2006-2007 academic year (Appendix A). Department (division) chairs received an email message directing them to a Web site where they were allowed to access an online questionnaire 
designed to collect demographic data and the Bar-On EQ-i instrument (Appendix C). The email message to department (division) chairs encouraged participation, explained the purpose of the study, and assured the anonymity of participants. The projected return rate was $80 \%$ of the department (division) chairs surveyed. Demographic data to be collected included: (a) gender, (b) age, (c) each chair's total years of experience as a chairperson, and (d) each chair's total years of experience as a chairperson in the current department or division (Appendix D).

The organizational climate description questionnaire for academic departments of colleges and universities (OCDQ-HE-Partial) was administered to 326 faculty members in the West Virginia State community college system (Appendix B). Faculty members received an email message directing them to a Web site where they were allowed to access an online questionnaire designed to collect demographic data and the OCDQ-HE-Partial instrument (Appendix E). The email message to faculty encouraged participation, explained the purpose of the study, and assured the anonymity of participants. The projected return rate was $50 \%$ of the department or division faculty members surveyed.

Faculty member demographic data collected included: (a) gender, (b) age, and (c) each faculty member's total years of teaching experience in the current department or division (Appendix F). Gender data were collected categorically for department chairs and faculty members, while all other demographic data was collected as continuous variables. To reduce the effects of response bias for department chairs and faculty members, this study assured participant anonymity. 


\section{Scoring EQ-i Instruments}

The first step in determining a respondent's EQ-i results is to calculate raw scores for the 15 subscales, five composite factors, total EQ, and validity scales. Each item is assigned "points" from one to five based on the respondent's responses. Some items are scored positively and some items are scored negatively. If a respondent replied "Very Often True of Me or True of Me" to a positively phrased item such as "I like everyone I meet," the respondent would receive five points. A response of "Very Seldom or Not True of Me" to this item or other positively phrased items would produce a score of one point and subsequently; "Often True of Me" would be scored as 4 points; "Sometimes" would be scored as 3 points; and "Seldom True of Me" would be scored as 2 points. If the respondent replied "Very Often True of Me or True of Me" to a negatively phrased item such as "It's hard for me to enjoy life," he or she would earn one point (reverse scored). A response of "Very Seldom or Not True of Me" to this item or other negatively phrased items would produce a score of five points; "Often True of Me" would be scored as 2 points; "Sometimes" would be scored as 3 points; and "Seldom True of Me" would be scored as 4 points. Bar-On (1997) reports that one hundred and seventeen of the EQ-i items are linked to one or more of the five composite factors and 15 subscales. The raw scores for the subscales and the composite factors are generated by adding the "points" from the applicable items, and the raw total EQ score is determined by summing the scores for these 117 items. Fifteen other items are related to the Positive Impression scale (8 items) and Negative Impression scale (7 items), and 
the raw scores for these scales are calculated like the total EQ score, five composite factors, and 15 subscales. For these scales, scores from one to five are awarded for each item, and the scores are summed to determine the raw scores. Results for the Inconsistency Index are obtained by comparing the responses to 10 pairs of similar items, and according to Bar-On (1997), if someone scores higher than 12 on the Inconsistency Index, the responses are likely invalid.

Bar-On (1997) reports that raw scores are nearly meaningless on their own; they do not allow for comparison between subscales, composite factors, or total EQ scores in and between respondents from the same population. As such, raw scores are converted to standard scores to facilitate comparison to the responses of the normative sample, which is representative of the general population. Raw scores are mathematically converted to standard scores through a statistical formula to ensure that each composite scale and subscale will have the same mean (100) and standard deviation (15) and that the respondent's age and gender are taken into account. An obtained standard score of 100 for any scale means that the respondent's score is exactly average, relative to the norms for people of the same gender and age group. Since the EQ-i is a copyrighted instrument owned by Multi-Health Systems, Inc (MHS), specific procedures and formulas to calculate the 15 subscales, five composite factors, total EQ, and validity scales were not revealed. An example of an EQ-i Individual Summary Report and Key are located in Appendix G. 


\section{Scoring OCDQ-HE-Partial Instruments}

Faculty members who responded to the OCDQ-HE-Partial survey answered the 42 questions by choosing one of five options, which were assigned the following Likert Scale: Almost never $=1$, Infrequently $=2$, Approximately equal $=3$, Frequently $=4$ and Almost always $=5$. An example OCDQ-HE-Partial Individual Summary Report is located in Appendix $\mathrm{H}$.

When scoring the OCDQ-HE-Partial, the scores for each survey respondent were sorted using the OCDQ-HE-Partial Key (Appendix $\mathrm{H})$ to identify the questions associated with the four subcategories of Consideration, Intimacy, Production Emphasis, and Disengagement. Faculty member scores in each subcategory were totaled and compared to their respective Chair's EQ-i composite category scores for Intrapersonal, Interpersonal, Adaptability, Stress Management, and General Mood using the Pearson Product Moment Correlation Test. The overall OCDQ-HE-Partial score was determined by adding the two positive subcategories of Consideration and Intimacy together and subtracting the sum of the two negative categories of Production Emphasis and Disengagement. The difference was reported as the overall OCDQ-HE-Partial score for each faculty member and the overall OCDQ-HE-Partial score was compared to their respective chair's overall EQ-i score using the Pearson Product Moment Correlation Test.

Analysis of Data

The Pearson product moment correlation test was used to analyze the continuous variable data collected from department chairs and faculty members 
in the West Virginia State community college system. Pearson's product moment correlation coefficient, usually denoted by $r$, is a measure of the linear association between two variables that have been measured on interval or ratio scales. The coefficient of determination $\left(r^{2}\right)$ was also reported, which is the ratio of the explained variation to the total variation, and it indicates the strength of the linear association between the $x$ and $y$ variables. The emotional intelligence competencies of department chairs and the faculty members' perceptions of organizational climate are ratio scaled variables, and Pearson product moment correlation test was utilized to measure the linear association between the two variables.

Chi square tests were used to analyze the nominal data collected from department chairs and faculty members in the West Virginia State community college system. Chi square is a non-parametric test of statistical significance for bivariate tabular analysis. The Chi square test was utilized to test the relationship (if any) between the nominal gender data and the categorical data collected for emotional intelligence competencies of department chairs and the faculty members' perceptions of organizational climate in the West Virginia State community college system. Post-hoc analyses was conducted where appropriate.

The procedures described in this chapter were designed to determine the relationship between the emotional intelligence competencies of department (division) chairs in the West Virginia State community college system and their faculty members' perceptions of organizational climate. The entire population of 
department (division) chairs and faculty members in West Virginia State community college system were surveyed, and test results will be shared with the participants of this study.

Schedule of Events

Subjects were emailed on November 14, 2006. Follow-up emails occurred on November 28, 2006 with subsequent requests beginning two weeks later on December 12, 2006. Analysis took place through March 30, 2007; the oral defense is scheduled for April of 2007; and graduation is anticipated in May of 2007. 


\section{Chapter 4}

\section{Presentation and Analysis of Data}

The purpose of this study was to examine the relationship between the emotional intelligence competencies of department chairs in the West Virginia State Community College System and their faculty members' perceptions of organizational climate. In this investigation, the independent variable was the emotional intelligence competencies of department chairs, and the dependent variable was faculty members' perceptions of organizational climate. Data were collected about the demographic variables of gender, age, years of experience, and years of experience in the current department.

The entire population $(\mathrm{N}=40)$ of department chairs in the West Virginia State Community College System was surveyed, as was the entire population $(\mathrm{N}=326)$ of faculty members. The Emotional Quotient Inventory (EQ-i) was used to collect data about each department chair (Appendix A). The response rate of chairs on the EQ-i was 83\% (N=33). The organizational climate description questionnaire for academic departments of colleges and universities (OCDQ-HEPartial) was used to collect data about faculty members' perceptions of organizational climate (Appendix B). Data were collected about the demographic variables of age, gender, and years of teaching experience in the current department at the time the OCDQ-HE-Partial surveys were conducted. The response rate of faculty members was $51 \%(\mathrm{~N}=165)$. The population and distribution of chairpersons and faculty members in the West Virginia State 
Community and Technical College System and the surveys' return frequencies and rates are indicated by Figure 4 .

\begin{tabular}{lcccccc}
\hline \hline WV State CTC & Chairs & $\begin{array}{c}\text { Chair Return } \\
\text { Frequency }\end{array}$ & $\begin{array}{c}\text { Chair Return } \\
\text { Rate }\end{array}$ & Faculty & $\begin{array}{c}\text { Faculty Return } \\
\text { Frequency }\end{array}$ & $\begin{array}{c}\text { Faculty Return } \\
\text { Rate }\end{array}$ \\
\hline Blue Ridge & 4 & 4 & $100 \%$ & 15 & 12 & $80 \%$ \\
\hline Marshall & 3 & 3 & $100 \%$ & 36 & 10 & $28 \%$ \\
\hline Northern & 4 & 3 & $75 \%$ & 52 & 19 & $37 \%$ \\
\hline Pierpont & 4 & 4 & $100 \%$ & 27 & 12 & $44 \%$ \\
\hline Southern & 6 & 6 & $100 \%$ & 70 & 38 & $35 \%$ \\
\hline WV-State & 4 & 1 & $25 \%$ & 31 & 57 & $71 \%$ \\
\hline WVU-P & 7 & 7 & $100 \%$ & 80 & 6 & $40 \%$ \\
\hline WVU-Tech & 8 & 5 & $63 \%$ & 15 & 165 & $51 \%$ \\
\hline \hline
\end{tabular}

Figure 4: This figure indicates the WV State CTC population and distribution of chairs and faculty and survey return frequencies and rates.

The results of this study are presented in the following sequence. First, a descriptive profile of the survey data is provided. Second, a description of the statistical analyses is detailed. Third, the major findings of the study are provided.

\section{Descriptive Data}

\section{Department Chair Data}

Of the 33 chairs responding to the EQ-i, 11 (33\%) were male and 22 (67\%) were female. The age of the chair respondents ranged from 39 years to 71 years with a mean of 53 years. All of the chairs reported total years of administrative experience and years of administrative experience in the current department. The range of total experience was from 1 to 39 years with a mean of 9 years. The range of experience in the current department was from 1 to 39 years with a mean of 7 years. All data collection instruments were assigned a number pre-coded to each chair to protect participant anonymity. 


\section{Faculty Data}

Of the faculty members responding to the OCDQ-HE-Partial $(N=165), 63$ (38\%) were male, and $102(62 \%)$ were female. The age of the faculty respondents ranged from 28 years to 70 years with a mean of 48 years. The range of teaching experience in the current department was from 1 to 37 years with a mean of 11 years. All data collection instruments were pre-coded with college and department name.

\section{Emotional Intelligence Competencies}

The Emotional Quotient Inventory assessed department chairs' emotional intelligence competencies. The chair emotional quotient scores ranged from 87 to 129 with a mean emotional quotient score of 105 , which is five points higher than the Bar-On EQ-i mean test score of 100 (Bar-On, 1997). Emotional intelligence data also were analyzed by age, total years of administrative experience, and years of administrative experience in the current department.

\section{Organizational Climate}

Adding the individual faculty member OCDQ-HE-Partial scores of each department and dividing by the total number of department faculty members determined each department's organizational climate score. The overall mean for organizational climate was 9 with a range from minus (-) 28 to positive (+) 50 . Organizational climate data of the faculty members were analyzed by gender, age, and years of teaching experience in the current department. 


\section{Statistical Analyses}

The independent variable in this study was the emotional intelligence competencies of department chairs. The control variables for department chairs were age, years of experience as chair, and years of experience as chair in the current position. For faculty, the control variables were gender, age, and years of teaching experience in the current department. The dependent variable was faculty members' perceptions of organizational climate. The statistical test used to investigate the relationship between the independent variable, the demographic variables, and the dependent variable was Pearson's Product Moment Correlation. Because the variables of emotional intelligence competencies, age, years of experience, and years of experience in the current department are continuous variables, the Pearson Product Moment Correlation was used to investigate the relationship between these variables and the dependent variable, faculty members' perceptions of organizational climate. Chi square tests were used to analyze the nominal research data collected, and results are presented in cross-tabulation (contingency table) format. Data from faculty members and department chairs were entered in a Microsoft Excel spreadsheet. Data were transferred into the Statistical Package for Social Sciences (SPSS) and all statistical analyses were manipulated by SPSS, version 11. An alpha level of .05 served as the level of significance for this study.

\section{Major Findings}

The major findings from this study are presented in this section. 
Research Question No. 1 - What relationship exists, if any, between the chairperson's levels of emotional intelligence competencies and organizational climate as perceived by faculty members in those departments or divisions? Chairs' Overall Emotional Quotient (EQ) and Organizational Climate

The relationship between department chairs' overall levels of emotional intelligence competencies and faculty members' overall perceptions of organizational climate was addressed by determining the correlation coefficient between the two variables (Table 1). The Pearson product-moment correlation test indicated that there was a statistically significant negative correlation between department chairs' overall levels of emotional intelligence competencies and faculty members' overall perceptions of organizational climate, $r(N=153)=$ $-0.268, p<.01\left(r^{2}=0.072\right)$. This correlation indicated that as total emotional quotient scores increased, total organizational climate scores decreased. The relationship between the two variables was statistically significant at the 0.01 level (Table 1).

Table 1

Correlation Between Emotional Quotient and Organizational Climate ( $N=153)$ Organizational Total EQ Climate

\begin{tabular}{cccc}
\hline $\begin{array}{c}\text { Organizational } \\
\text { Climate }\end{array}$ & $\begin{array}{c}\text { Pearson } \\
\text { Correlation } \\
\text { Sig. (2-tailed) }\end{array}$ & 1.00 & $-0.268^{\star \star}$ \\
& $\mathrm{N}$ & 153 & 0.001 \\
Total EQ & $\begin{array}{c}\text { Pearson } \\
\text { Correlation }\end{array}$ & $-0.268^{\star *}$ & 153 \\
& $\begin{array}{c}\text { Sig. (2-tailed) } \\
\text { N }\end{array}$ & 0.001 & 1.00 \\
& 153 & \\
& & & 153 \\
\hline
\end{tabular}

** Significant $p<0.01$ 


\section{Chairs' EQ Composite Categories and Organizational Climate Subcategories}

The relationship between the department chairs' five composite categories of emotional intelligence competencies and the faculty members' four subcategories of organizational climate was addressed by determining the correlation coefficient between the variables (Tables 2-6).

The Pearson product-moment correlation test indicated that there was a statistically significant positive correlation between the emotional quotient Intrapersonal composite category and the organizational climate subcategory of Disengagement and a statistically significant negative correlation between the emotional quotient Intrapersonal composite category and the organizational climate subcategory of Consideration. The correlation coefficient for Disengagement was $r(\mathrm{~N}=153)=0.350, p<.01\left(r^{2}=0.123\right)$ and the correlation coefficient for Consideration was $r(\mathrm{~N}=153)=-0.196, p<.05\left(r^{2}=0.038\right)$. This correlation indicated that as the Intrapersonal composite category scores increased, the organizational climate subcategory Disengagement scores also increased and the Consideration subcategory scores decreased. The relationship between the Intrapersonal composite category and the Disengagement subcategory was statistically significant at the 0.01 level, and the relationship between Intrapersonal composite category and the Consideration subcategory was statistically significant at the 0.05 level. The Pearson product-moment correlation test did not indicate significant correlations between the emotional 
quotient composite category of Intrapersonal and the organizational climate subcategories of Production and Intimacy (Table 2).

Table 2

Correlation Between the EQ Intrapersonal Category and OCDQ-HE Subcategories ( $N=153$ )

\begin{tabular}{|c|c|c|c|c|c|c|}
\hline & & Intrapersonal & Production & "Disengagement & Consideration & Intimacy \\
\hline Intrapersonal & $\begin{array}{l}\text { Pearson Correlation } \\
\text { Sig. (2-tailed) }\end{array}$ & 1 & & & & \\
\hline Production & $\begin{array}{l}\text { Pearson Correlation } \\
\text { Sig. (2-tailed) }\end{array}$ & $\begin{array}{r}-0.024 \\
0.772\end{array}$ & $\begin{array}{l}1 \\
\text {. }\end{array}$ & & & \\
\hline Disengagement & $\begin{array}{l}\text { Pearson Correlation } \\
\text { Sig. (2-tailed) }\end{array}$ & $\begin{array}{l}0.350 * \\
0.000\end{array}$ & $\begin{array}{l}-0.405^{* *} \\
0.000\end{array}$ & 1 & & \\
\hline Consideration & $\begin{array}{l}\text { Pearson Correlation } \\
\text { Sig. (2-tailed) }\end{array}$ & $\begin{array}{r}-0.196 \\
0.015\end{array}$ & $\begin{array}{l}0.754^{* *} \\
0.000\end{array}$ & $\begin{array}{l}-0.487 \text { ** } \\
0.000\end{array}$ & 1 & \\
\hline Intimacy & $\begin{array}{l}\text { Pearson Correlation } \\
\text { Sig. (2-tailed) }\end{array}$ & $\begin{array}{r}-0.139 \\
0.086 \\
\end{array}$ & $\begin{array}{l}0.611 \text { ** } \\
0.000\end{array}$ & $\begin{array}{l}-0.425^{* *} \\
0.000\end{array}$ & $\begin{array}{l}0.655 \text { ** } \\
0.000\end{array}$ & 1 \\
\hline
\end{tabular}

${ }^{*}$ Correlation is significant at the 0.05 level

${ }^{* *}$ Correlation is significant at the 0.01 level

The Pearson product-moment correlation test indicated that there was a statistically significant positive correlation between the emotional quotient Interpersonal composite category and the organizational climate subcategory of Disengagement, $r(\mathrm{~N}=153)=0.244, p<.01\left(r^{2}=0.059\right)$. This correlation indicated that as the Interpersonal composite category scores increased, the organizational climate Disengagement category scores also increased. The relationship between the Interpersonal composite category and the Disengagement subcategory was statistically significant at the 0.01 level. The Pearson product-moment correlation test did not indicate significant correlations between the emotional quotient composite category of Interpersonal and the organizational climate subcategories of Production, Consideration, and Intimacy (Table 3). 
Table 3

Correlation Between the EQ Interpersonal Category and OCDQ-HE Subcategories ( $N=153)$

\begin{tabular}{|c|c|c|c|c|c|c|}
\hline & & Interpersonal & Production & "Disengagement & Consideration & Intimacy \\
\hline \multirow[t]{2}{*}{ Interpersonal } & Pearson Correlation & 1 & & & & \\
\hline & Sig. (2-tailed) & . & & & & \\
\hline \multirow[t]{2}{*}{ Production } & Pearson Correlation & -0.012 & 1 & & & \\
\hline & Sig. (2-tailed) & 0.886 & . & & & \\
\hline \multirow[t]{2}{*}{ Disengagement } & Pearson Correlation & $0.244 * *$ & -0.405 ** & 1 & & \\
\hline & Sig. (2-tailed) & 0.002 & 0.000 & . & & \\
\hline \multirow[t]{2}{*}{ Consideration } & Pearson Correlation & -0.143 & 0.754 ** & -0.487 ** & 1 & \\
\hline & Sig. (2-tailed) & 0.077 & 0.000 & 0.000 & . & \\
\hline \multirow[t]{2}{*}{ Intimacy } & Pearson Correlation & -0.030 & 0.611 ** & $-0.425 * *$ & 0.655 ** & 1 \\
\hline & Sig. (2-tailed) & 0.716 & 0.000 & 0.000 & 0.000 & \\
\hline
\end{tabular}

** Correlation is significant at the 0.01 level

The Pearson product-moment correlation test indicated that there was a statistically significant positive correlation between the emotional quotient Stress composite category and the organizational climate subcategory of Disengagement, $r(\mathrm{~N}=153)=0.195, p<.05\left(r^{2}=0.038\right)$ (Table 4). This correlation indicated that as the Stress composite category scores increased, the organizational climate Disengagement category scores also increased. The relationship between the Stress composite category and the Disengagement subcategory was statistically significant at the 0.05 level. The Pearson productmoment correlation test did not indicate significant correlations between the emotional quotient composite category of Stress and the organizational climate subcategories of Production, Consideration, and Intimacy. 
Table 4

Correlation Between the EQ Stress Category and OCDQ-HE Subcategories $(N=153)$

\begin{tabular}{|c|c|c|c|c|c|c|}
\hline & & Stress & Production & Disengagement & Consideration & Intimacy \\
\hline Stress & $\begin{array}{l}\text { Pearson Correlation } \\
\text { Sig. (2-tailed) }\end{array}$ & 1 & & & & \\
\hline Production & $\begin{array}{l}\text { Pearson Correlation } \\
\text { Sig. (2-tailed) }\end{array}$ & $\begin{array}{l}0.018 \\
0.821\end{array}$ & 1 & & & \\
\hline Disengagement & $\begin{array}{l}\text { Pearson Correlation } \\
\text { Sig. (2-tailed) }\end{array}$ & $\begin{array}{l}0.195 \\
0.016\end{array}$ & $\begin{array}{l}-0.405 \text { ** } \\
0.000\end{array}$ & 1 & & \\
\hline Consideration & $\begin{array}{l}\text { Pearson Correlation } \\
\text { Sig. (2-tailed) }\end{array}$ & $\begin{array}{l}0.001 \\
0.994\end{array}$ & $\begin{array}{l}0.754 \text { ** } \\
0.000\end{array}$ & $\begin{array}{l}-0.487 \text { ** } \\
0.000\end{array}$ & 1 & \\
\hline Intimacy & $\begin{array}{l}\text { Pearson Correlation } \\
\text { Sig. (2-tailed) }\end{array}$ & $\begin{array}{l}0.000 \\
0.998\end{array}$ & $\begin{array}{l}0.611 \text { ** } \\
0.000\end{array}$ & $\begin{array}{l}-0.425^{* *} \\
0.000\end{array}$ & $\begin{array}{l}0.655 \text { ** } \\
0.000\end{array}$ & 1 \\
\hline
\end{tabular}

${ }^{*}$ Correlation is significant at the 0.05 level

${ }^{*}$ Correlation is significant at the 0.01 level

The Pearson product-moment correlation test indicated that there was a statistically significant positive correlation between the emotional quotient Adaptability composite category and the organizational climate subcategory of Disengagement, $r(\mathrm{~N}=153)=0.283, p<.01\left(r^{2}=0.080\right)($ Table 5$)$. This correlation indicated that as the Adaptability composite category scores increased, the organizational climate Disengagement category scores also increased. The relationship between the Adaptability composite category and the Disengagement subcategory was statistically significant at the 0.01 level. The Pearson product-moment correlation test did not indicate significant correlations between the emotional quotient composite category of Adaptability and the organizational climate subcategories of Production, Consideration, and Intimacy. 
Table 5

Correlation Between the EQ Adaptability Category and OCDQ-HE Subcategories ( $N=153)$

\begin{tabular}{|c|c|c|c|c|c|c|}
\hline & & Adaptability & Production & Disengagement & Consideration & Intimacy \\
\hline Adaptability & $\begin{array}{l}\text { Pearson Correlation } \\
\text { Sig. (2-tailed) }\end{array}$ & 1 & & & & \\
\hline Production & Pearson Correlation & 0.008 & 1 & & & \\
\hline & Sig. (2-tailed) & 0.922 & . & & & \\
\hline Disengagement & $\begin{array}{l}\text { Pearson Correlation } \\
\text { Sig. (2-tailed) }\end{array}$ & $\begin{array}{l}0.283^{* *} \\
0.000\end{array}$ & $\begin{array}{l}-0.405 * * \\
0.000\end{array}$ & 1 & & \\
\hline Consideration & $\begin{array}{l}\text { Pearson Correlation } \\
\text { Sig. (2-tailed) }\end{array}$ & $\begin{array}{r}-0.072 \\
0.374\end{array}$ & $\begin{array}{l}0.754 \text { ** } \\
0.000\end{array}$ & $\begin{array}{l}-0.487 \text { ** } \\
0.000\end{array}$ & 1 & \\
\hline Intimacy & $\begin{array}{l}\text { Pearson Correlation } \\
\text { Sig. (2-tailed) }\end{array}$ & $\begin{array}{r}-0.037 \\
0.649\end{array}$ & $\begin{array}{l}0.611 \text { ** } \\
0.000\end{array}$ & $\begin{array}{l}-0.425^{* *} \\
0.000\end{array}$ & $\begin{array}{l}0.655 \text { ** } \\
0.000\end{array}$ & 1 \\
\hline
\end{tabular}

${ }^{* \star}$ Correlation is significant at the 0.01 level

The Pearson product-moment correlation test indicated that there was a statistically significant positive correlation between the emotional quotient General Mood composite category and the organizational climate subcategory of Disengagement, $r(\mathrm{~N}=153)=0.226, p<.01\left(r^{2}=0.060\right)$ (Table 6). This correlation indicated that as the General Mood composite category scores increased, the organizational climate Disengagement category scores also increased. The relationship between the General Mood composite category and the Disengagement subcategory was statistically significant at the 0.01 level. The Pearson product-moment correlation test did not indicate significant correlations between the emotional quotient composite category of General Mood and the organizational climate subcategories of Production, Consideration, and Intimacy. 
Table 6

Correlation Between the EQ General Mood Category and OCDQ-HE Categories ( $N=153)$

\begin{tabular}{|c|c|c|c|c|c|c|}
\hline & & General Mood & $\begin{array}{l}\text { Production } \\
\end{array}$ & Disengagement & Consideration & Intimacy \\
\hline General Mood & $\begin{array}{l}\text { Pearson Correlation } \\
\text { Sia. (2-tailed) }\end{array}$ & 1 & & & & \\
\hline Production & $\begin{array}{l}\text { Pearson Correlation } \\
\text { Sin (2-tailer) }\end{array}$ & $\begin{array}{l}0.075 \\
0354\end{array}$ & 1 & & & \\
\hline Disengagement & $\begin{array}{l}\text { Pearson Correlation } \\
\text { Sig. (2-tailed) }\end{array}$ & $\begin{array}{l}0.226 \text { *夫 } \\
0.005\end{array}$ & $\begin{array}{l}-0.405 \text { ** } \\
0.000\end{array}$ & 1 & & \\
\hline Consideration & $\begin{array}{l}\text { Pearson Correlation } \\
\text { Siq. (2-tailed) }\end{array}$ & $\begin{array}{r}-0.035 \\
0.669\end{array}$ & $\begin{array}{l}0.754 * * \\
0.000\end{array}$ & $\begin{array}{l}-0.487 \text { ** } \\
0.000\end{array}$ & & \\
\hline Intimacy & $\begin{array}{l}\text { Pearson Correlation } \\
\text { Sig. (2-tailed) }\end{array}$ & $\begin{array}{r}-0.033 \\
0.689\end{array}$ & $\begin{array}{l}0.611 \text { * } \\
0.000\end{array}$ & $\begin{array}{l}-0.425 \text { * } \\
0.000\end{array}$ & $\begin{array}{l}0.655^{* *} \\
0.000\end{array}$ & 1 \\
\hline
\end{tabular}

${ }^{* \star}$ Correlation is significant at the 0.01 level

Research Question No. 2 - What relationship exists, if any, between (a) age, gender, years of experience as a chairperson, years of experience as

chairperson in the current department or division, and (b) the emotional intelligence competencies of chairpersons and (c) organizational climate as perceived by faculty members in those departments or divisions? Chairs' Age and Experience and Emotional Intelligence Competencies

The relationships between chairpersons' age, total administrative experience, and administrative experience in the current department or division and their emotional intelligence competencies were addressed by determining the correlation coefficients between the variables (Table 7). The Pearson product-moment correlation test indicated that there was a statistically significant positive correlation between chairpersons' age and their emotional intelligence competencies, $r(\mathrm{~N}=33)=0.414, p<.01\left(r^{2}=0.171\right)$. This correlation indicated that as the age of chairpersons increased, total EQ-i scores also increased. The relationship between the two variables was significant at the 0.01 level (Table 7). 
However, the Pearson product-moment correlation test did not indicate significant correlations between the chairpersons' total administrative experience and administrative experience in the current department or division and their emotional intelligence competencies.

Table 7

Correlation Between Emotional Quotient and Chair Age, Total Administrative Experience, and Administrative Experience in the Current Department or Division ( $N=33$ )

\begin{tabular}{|c|c|c|c|c|c|}
\hline & & Q-i & $\overline{\text { Age }}$ & $\overline{\text { Total Experience }}$ & Current Experience \\
\hline$\overline{\text { EQ-i }}$ & $\begin{array}{l}\text { Pearson Correlation } \\
\text { Sig. (2-tailed) }\end{array}$ & $\overline{1}$ & & & \\
\hline Age & $\begin{array}{l}\text { Pearson Correlation } \\
\text { Sig. (2-tailed) }\end{array}$ & $\begin{array}{l}0.414^{* *} \\
0.017\end{array}$ & 1 & & \\
\hline Total Experience & $\begin{array}{l}\text { Pearson Correlation } \\
\text { Sig. (2-tailed) }\end{array}$ & $\begin{array}{l}0.249 \\
0.162\end{array}$ & $\begin{array}{l}0.558 * * \\
0.001\end{array}$ & 1 & \\
\hline Current Experience & $\begin{array}{l}\text { Pearson Correlation } \\
\text { Sig. (2-tailed) }\end{array}$ & $\begin{array}{l}0.140 \\
0.437\end{array}$ & $\begin{array}{l}0.533 \text { * } \\
0.001\end{array}$ & $\begin{array}{l}0.887 \text { * } \\
0.000\end{array}$ & 1 \\
\hline
\end{tabular}

** Correlation is significant at the 0.01 level

${ }^{*}$ Correlation is significant at the 0.05 level

\section{Chairs' Gender and Emotional Intelligence Competencies}

The relationship between chairpersons' gender and chairpersons' emotional intelligence competencies was addressed by creating a crosstabulation table (Table 8). These data were divided into two categories representing the lower 50 percent of chairpersons' EQ-i scores and the upper 50 percent of chairpersons' EQ-i scores. These data indicate that there is not a statistically significant difference between EQ-i scores for female chairpersons as compared to male chairpersons, $X^{2}(1, N=33)=0.15, p<1$. Table 8 shows the distribution of the number and percent of chairpersons in each category of EQ-i based on the gender of the chairperson. 
Table 8

Chairpersons' EQ-i by Gender ( $N=33$ )

\begin{tabular}{|c|c|c|c|c|c|c|}
\hline \multirow[b]{3}{*}{ EQ-i } & \multicolumn{6}{|c|}{ Chairperson Gender } \\
\hline & \multicolumn{2}{|c|}{ Female } & \multicolumn{2}{|c|}{ Male } & \multicolumn{2}{|c|}{ Total } \\
\hline & $\mathrm{N}$ & $\%$ & $\mathrm{~N}$ & $\%$ & $\mathrm{~N}$ & $\%$ \\
\hline Lower $50 \%$ & 14 & 64 & 7 & 64 & 21 & 64 \\
\hline Upper 50\% & 8 & 36 & 4 & 36 & 12 & 36 \\
\hline Total & 22 & 100 & 11 & 100 & 33 & 100 \\
\hline
\end{tabular}

Chi-square $=0.15$ and $p$ is less than or equal to 1 .

The distribution is not significant.

Chairs' Age and Experience and Organizational Climate (OCDQ)

The relationship between chairpersons' age, total administrative experience, and administrative experience in the current department or division and their faculty members' perception of organizational climate were addressed by determining the correlation coefficients between the variables (Table 9). The Pearson product-moment correlation test indicated that there was a statistically significant negative correlation between chairpersons' age, $r(N=153)=-0.289$, $p<.01\left(r^{2}=0.084\right)$, total administrative experience, $r(N=153)=-0.172, p<.05$ $\left(r^{2}=0.030\right)$, and administrative experience in the current department or division, $r(\mathrm{~N}=153)=-0.179, p<.05\left(r^{2}=0.032\right)$, and their faculty members' perceptions of organizational climate. These correlations indicated that as the age, total administrative experience, and administrative experience in the current department or division of the chairpersons increased, faculty members' perception of organizational climate (OCDQ-HE-Partial) decreased. The relationship between chairpersons' age and OCDQ-HE-Partial was significant at the 0.01 level, and the relationship between chairpersons' total administrative 
experience and administrative experience in the current department or division and OCDQ-HE-Partial was significant at the 0.05 level (Table 9).

Table 9

Correlation Between Organizational Climate and Chair Age, Total Administrative Experience, and Administrative Experience in the Current Department or Division ( $N=153$ )

\begin{tabular}{|c|c|c|c|c|c|}
\hline & & $\overline{\mathrm{CDQ}-\mathrm{HE}}$ & $\overline{\overline{\text { Age }}}$ & "Total Experience & Current Experience \\
\hline$\overline{\mathrm{OCDQ}}-\mathrm{HE}$ & $\begin{array}{l}\text { Pearson Correlation } \\
\text { Sig. (2-tailed) }\end{array}$ & $\overline{1}$ & & & \\
\hline Age & $\begin{array}{l}\text { Pearson Correlation } \\
\text { Sig. (2-tailed) }\end{array}$ & $\begin{array}{l}-0.289 * * \\
0.000\end{array}$ & 1 & & \\
\hline Total Experience & $\begin{array}{l}\text { Pearson Correlation } \\
\text { Sia. (2-tailed) }\end{array}$ & $\begin{array}{l}-0.172 \text { * } \\
0.033\end{array}$ & $\begin{array}{l}0.548 \text { * } \\
0.000\end{array}$ & 1 & \\
\hline Current Experience & $\begin{array}{l}\text { Pearson Correlation } \\
\text { Sig. (2-tailed) }\end{array}$ & $\begin{array}{l}-0.179 * \\
0.027\end{array}$ & $\begin{array}{l}0.503 \text { ** } \\
0.000\end{array}$ & $\begin{array}{l}0.904 \text { ** } \\
0.000\end{array}$ & 1 \\
\hline
\end{tabular}

$\overline{{ }^{*} \text { Correlation is significant at the } 0.01 \text { level }}$

${ }^{*}$ Correlation is significant at the 0.05 level

\section{Chairpersons' Gender and Organizational Climate}

The relationship between chairpersons' gender and organizational climate was addressed by creating a cross-tabulation table, and data was categorized into quartiles (Table 10). When categorized into quartiles, data revealed that $56 \%$ of faculty members rated organizational climate in the top two quartiles for female chairs as compared to $48 \%$ of the faculty members who rated organizational climate in the top two quartiles for male chairs. These data indicate that there is a statistically significant difference between OCDQ-HE-Partial scores for female chairpersons as compared to male chairpersons, $X^{2}(3, N=153)=8.973, p<$ .05 , and that faculty members perceive organizational climate to be more positive for female chairpersons than male chairpersons. Table 10 shows the distribution of the number and percent of chairpersons in each quartile of OCDQ-HE-Partial based on the gender of the chairperson. 
Table 10

Chairpersons' OCDQ-HE by Gender (N=153)

\begin{tabular}{ccccccc}
\hline \hline & \multicolumn{5}{c}{ Chairperson Gender } \\
Quartiles of OCDQ-HE & $\mathrm{N}$ & $\%$ & $\mathrm{~N}$ & $\%$ & $\mathrm{~N}$ & $\%$ \\
\cline { 2 - 7 } & 9 & 9 & 12 & 21 & 21 & 14 \\
2 & 33 & 35 & 18 & 31 & 51 & 33 \\
3 & 44 & 47 & 28 & 48 & 72 & 47 \\
4 & 9 & 9 & 0 & 0 & 9 & 6 \\
Total & 95 & 100 & 58 & 100 & 153 & 100 \\
\hline \hline
\end{tabular}

Chi-square $=8.973$ and $p$ is less than or equal to 0.05 .

The distribution is significant.

Research Question 3 - What relationship exists, if any, between age, gender, years of teaching experience as a faculty member in the current department or division, and organizational climate as perceived by faculty members in those departments or divisions?

Faculty Members' Age and Experience and Organizational Climate

The relationship between faculty members' age and experience and faculty members' overall perceptions of organizational climate (OCDQ-HEPartial) was addressed by determining the correlation coefficient between the variables (Table 11). The Pearson product-moment correlation test did not indicate a statistically significant correlation between faculty members' age and faculty members' overall perceptions of organizational climate. However, the Pearson product-moment correlation test did indicate a statistically significant negative correlation between faculty members' experience and faculty members' overall perceptions of organizational climate, $r(N=165)=-0.228, p<.01\left(r^{2}=\right.$ 0.052), which indicates as faculty members' experience increases, then faculty members' perceptions of organizational climate decreases. 
Table 11

Correlation Between Organizational Climate and Faculty Member Age and Experience in the Current Department or Division ( $N=165)$

\begin{tabular}{llccc}
\hline \hline & & OCDQ-HE & Age & Total Experience \\
\hline OCDQ-HE & Pearson Correlation & 1 & & \\
\multirow{2}{*}{ Age } & Sig. (2-tailed) &. & & \\
\multirow{2}{*}{ Total Experience } & Pearson Correlation & -0.130 & 1 & \\
& Sig. (2-tailed) & 0.096 &. & 1 \\
& Pearson Correlation & $-0.228 * *$ & $0.518 * * *$ & .000 \\
& Sig. (2-tailed) & 0.003 & 0.000 &. \\
\hline \hline
\end{tabular}

${ }^{* \star}$ Correlation is significant at the 0.01 level

Faculty Members' Gender and Organizational Climate

The relationship between faculty members' gender and faculty members' overall perceptions of organizational climate was addressed by creating a crosstabulation table, and data was categorized into quartiles (Table 12). These data indicate no statistically significant difference between faculty members' perceptions of organizational climate for female faculty members as compared to male faculty members, $x^{2}(3, N=165)=2.548, p<1$. Table 12 shows the distribution of the number and percent of faculty members in each quartile of perceptions of organizational climate based on the gender of the faculty members.

Table 12

Faculty Members' OCDQ-HE by Gender ( $N=165)$

\begin{tabular}{ccccccc}
\hline \hline & \multicolumn{5}{c}{ Faculty Member Gender } \\
Quartiles of OCDQ-HE & $\mathrm{N}$ & $\%$ & $\mathrm{~N}$ & $\%$ & $\mathrm{~N}$ & $\%$ \\
\cline { 2 - 7 } & 15 & 15 & 10 & 16 & 25 & 15 \\
2 & 35 & 34 & 18 & 29 & 53 & 32 \\
3 & 44 & 43 & 33 & 52 & 77 & 47 \\
4 & 8 & 8 & 2 & 3 & 10 & 6 \\
Total & 102 & 100 & 63 & 100 & 165 & 100 \\
\hline \hline
\end{tabular}

Chi-square $=2.548$ and $p$ is less than or equal to 1 .

The distribution is not significant. 


\section{Ancillary Findings}

\section{Chairs' Emotional Intelligence Competencies}

The Emotional Quotient Inventory provides scores for Total Emotional Quotient (EQ), scores on each of the 5 composite scales, and scores on each of the 15 subscales. These scores are based on a mean of 100 and a standard deviation of 15 (Bar-On, 1997). Scores are classified as follows: markedly low (<70), very low (70-79), low (80-89), average (90-110) high (110-119), very high (120-129), and markedly high (130+). These classifications indicate areas for development (markedly low to low), areas of typical healthy functioning (average), or areas of strength (high to markedly high) (Bar-On, 1997). Multi-Health Systems, a firm that sells, conducts training on the use of, and analyzes results of the Emotional Quotient Inventory, provided results of the analyses of the Emotional Quotient Inventories administered in this study.

The mean Emotional Quotient (EQ) score for the group of chairs in this study is 105 with a standard deviation of 11 , which is within the average EQ range established by Bar-On in his 1997 study (Bar-On, 1997). Individual total Emotional Quotient (EQ) scores in this study ranged from a low of 87 (slightly less than 2 standard deviations below the mean) to a high of 129 (slightly greater than 2 standard deviations above the mean). A distribution of individual Total Emotional Quotient scores for the participants is shown in Table 13. The EQ-i reports for all the chairs indicate that the scores on the validity measures are all within the acceptable range. Therefore, the validity of the results is supported. 


\section{Table 13}

Distribution of Chairpersons' $E Q-i$ Scores ( $N=33$ )

\begin{tabular}{ccccccccc}
\hline & \multicolumn{6}{c}{ Basic Interpretation of Total Emotional Quotient (EQ) Scores } \\
& $\begin{array}{c}\text { Markedly } \\
\text { Low }\end{array}$ & $\begin{array}{c}\text { Very } \\
\text { Low }\end{array}$ & Low & Average & High & Very & Markedly \\
& $(<70)$ & $(70-79)$ & $(80-89)$ & $(90-109)$ & $(110-119)$ & $(120-129)$ & $130+$ \\
\hline Total EQ-i & 0 & 0 & 1 & 22 & 7 & 3 & 0
\end{tabular}

Chairs' Total Emotional Quotient (EQ) and Gender

Twenty-two female chairs and eleven male chairs participated in this study. Analysis of the mean scores for males and females indicates that the mean total EQ for male chairs was 104 and the mean total EQ for female chairs was 105. Twenty-two (67\%) chairs scored in the average range; ten (30\%) chairs scored above average; and one (3\%) chair scored in the below average range. Fifteen (68\%) of the chairs scoring in the average range were female, and seven (70\%) of the chairs scoring above average were female. Conversely, seven of the chairs (32\%) scoring in the average range were male, and three of the chairs (30\%) scoring above average were male. Table 14 illustrates the distribution of total EQ scores for the chairs by gender.

Table 14

Distribution of Chairpersons' $E Q-i$ Scores by Gender ( $N=33$ )

\begin{tabular}{|c|c|c|c|c|c|c|c|}
\hline & \multicolumn{7}{|c|}{ Basic Interpretation of Total Emotional Quotient (EQ) Scores } \\
\hline & Markedly & Very & Low & Average & High & Very & Markedly \\
\hline & Low & Low & & & & High & High \\
\hline & $(<70)$ & $(70-79)$ & (80-89) & (90-109) & $(110-119)$ & $(120-129)$ & $130+$ \\
\hline Total EQ-i & 0 & 0 & 1 & 22 & 7 & 3 & 0 \\
\hline $\begin{array}{l}\text { Total EQ-i } \\
\text { (Female) }\end{array}$ & 0 & 0 & 0 & 15 & 4 & 3 & 0 \\
\hline $\begin{array}{c}\text { Total EQ-i } \\
\text { (Male) }\end{array}$ & 0 & 0 & 1 & 7 & 3 & 0 & 0 \\
\hline
\end{tabular}


Chairs' Total Emotional Quotient (EQ) and Age

The age of the chairs participating in this study ranged from 39 years to 71 years, and the mean age was 53 years. Of the 33 chairs surveyed, two (6\%) of the chairs were in the 30 to 39 age range with a mean emotional quotient (EQ) score of 93 . Nine chairs $(27 \%)$ were in the $40-49$ age range with a mean EQ score of 100. Fifteen chairs (46\%) were in the $50-59$ age range with a mean EQ score of 107. Six chairs (18\%) were in the $60-69$ age range with a mean EQ score of 111 , and one chair (3\%) was in the 70+ age range with an EQ score of 103 . Table 15 shows chair EQ distribution by age range, and Table 16 illustrates the relationship between chairpersons' age groups and their emotional intelligence competencies.

\section{Table 15}

Distribution of Chairpersons'EQ-i Scores by Age ( $N=33)$

\begin{tabular}{|c|c|c|c|c|c|c|c|}
\hline & \multicolumn{7}{|c|}{ Basic Interpretation of Total Emotional Quotient (EQ) Scores } \\
\hline & $\begin{array}{c}\text { Markedly } \\
\text { Low } \\
(<70)\end{array}$ & $\begin{array}{l}\text { Very } \\
\text { Low } \\
(70-79)\end{array}$ & $\begin{array}{l}\text { Low } \\
\text { (80-89) }\end{array}$ & $\begin{array}{l}\text { Average } \\
(90-109)\end{array}$ & $\begin{array}{c}\text { High } \\
\text { (110-119) }\end{array}$ & $\begin{array}{c}\text { Very } \\
\text { High } \\
(120-129)\end{array}$ & $\begin{array}{c}\text { Markedly } \\
\text { High } \\
130+\end{array}$ \\
\hline $\begin{array}{l}\text { Total EQ-i } \\
\text { Age } 20-29\end{array}$ & 0 & 0 & 0 & 0 & 0 & 0 & 0 \\
\hline $\begin{array}{l}\text { Total EQ-i } \\
\text { Age } 30-39\end{array}$ & 0 & 0 & 0 & 2 & 0 & 0 & 0 \\
\hline $\begin{array}{l}\text { Total EQ-i } \\
\text { Age } 40-49\end{array}$ & 0 & 0 & 0 & 8 & 1 & 0 & 0 \\
\hline $\begin{array}{l}\text { Total EQ-i } \\
\text { Age } 50-59\end{array}$ & 0 & 0 & 1 & 8 & 4 & 2 & 0 \\
\hline $\begin{array}{l}\text { Total EQ-i } \\
\text { Age } 60-69\end{array}$ & 0 & 0 & 0 & 3 & 2 & 1 & 0 \\
\hline $\begin{array}{c}\text { Total EQ-i } \\
\text { Age } 70+\end{array}$ & 0 & 0 & 0 & 1 & 0 & 0 & 0 \\
\hline
\end{tabular}




\section{Chairs' Age Groups and Total Emotional Quotient (EQ)}

The relationship between the chairpersons' age groups and their emotional intelligence competencies was addressed by determining the correlation coefficients between the variables (Table 16). The Pearson productmoment correlation test indicated that there was a statistically significant positive correlation between chairpersons' age groups and their emotional intelligence competencies, $r(\mathrm{~N}=4)=0.995, p<.01\left(r^{2}=0.990\right)$. This correlation indicated that as the age of chairpersons increased, total EQ-i scores also increased. The relationship between the two variables was significant at the 0.01 level (Table 16).

Table 16

Correlation Between Chairpersons' Age Groups and Emotional Quotient $(N=4)$

\begin{tabular}{cccc}
\hline & & Age Groups & Total EQ \\
\hline Age Groups & Pearson & 1.00 & $0.995^{\star *}$ \\
& Correlation & & \\
& Sig. (2-tailed) & & 0.005 \\
Total EQ & $\mathrm{N}$ & 4 & 4 \\
& Pearson & $0.995^{\star \star}$ & 1.00 \\
& $\begin{array}{c}\text { Correlation } \\
\text { Sig. (2-tailed) } \\
\mathrm{N}\end{array}$ & 0.005 & \\
& $\mathrm{~N}$ & 4 \\
\hline \hline
\end{tabular}

** Significant $p<0.01$

Chairs' Total Emotional Quotient (EQ) and Experience

The years of experience of the chairs participating in this study ranged from one year to 39 years with a mean of 9 years. Of the 33 chairs surveyed, fifteen (46\%) of the chairs have 1-5 years of experience. Nine chairs (27\%) have 
6-10 years of experience. Three chairs (9\%) have 11-15 years of experience.

Four chairs (12\%) have 16-20 years of experience. One chair (3\%) has $21-25$

years of experience, and one chair (3\%) has 36-40 years of experience. Table 17 shows chair EQ distribution by years of experience as chair.

\section{Table 17}

Distribution of Chairpersons' EQ-i Scores by Years of Experience as Chair ( $N=33$ )

\begin{tabular}{|c|c|c|c|c|c|c|c|}
\hline & \multicolumn{7}{|c|}{ Basic Interpretation of Total Emotional Quotient (EQ) Scores } \\
\hline & $\begin{array}{l}\text { Markedly } \\
\text { Low } \\
(<70)\end{array}$ & $\begin{array}{l}\text { Very } \\
\text { Low } \\
(70-79)\end{array}$ & $\begin{array}{l}\text { Low } \\
\text { (80-89) }\end{array}$ & $\begin{array}{l}\text { Average } \\
(90-109)\end{array}$ & $\begin{array}{c}\text { High } \\
(110-119)\end{array}$ & $\begin{array}{c}\text { Very } \\
\text { High } \\
(120-129)\end{array}$ & $\begin{array}{c}\text { Markedly } \\
\text { High } \\
130+\end{array}$ \\
\hline $\begin{array}{l}\text { Total EQ-i } \\
\text { Years 1-5 }\end{array}$ & 0 & 0 & 1 & 10 & 4 & 0 & 0 \\
\hline $\begin{array}{l}\text { Total EQ-i } \\
\text { Years 6-10 }\end{array}$ & 0 & 0 & 0 & 7 & 1 & 1 & 0 \\
\hline $\begin{array}{c}\text { Total EQ-i } \\
\text { Years 11-15 }\end{array}$ & 0 & 0 & 0 & 1 & 1 & 1 & 0 \\
\hline $\begin{array}{c}\text { Total EQ-i } \\
\text { Years 16-20 }\end{array}$ & 0 & 0 & 0 & 2 & 1 & 1 & 0 \\
\hline $\begin{array}{c}\text { Total EQ-i } \\
\text { Years } 21-25\end{array}$ & 0 & 0 & 0 & 1 & 0 & 0 & 0 \\
\hline $\begin{array}{c}\text { Total EQ-i } \\
\text { Years 26-30 }\end{array}$ & 0 & 0 & 0 & 0 & 0 & 0 & 0 \\
\hline $\begin{array}{c}\text { Total EQ-i } \\
\text { Years 31-35 }\end{array}$ & 0 & 0 & 0 & 0 & 0 & 0 & 0 \\
\hline $\begin{array}{c}\text { Total EQ-i } \\
\text { Years 36-40 }\end{array}$ & 0 & 0 & 0 & 1 & 0 & 0 & 0 \\
\hline
\end{tabular}

Faculty Members' Age and Experience and OCDQ Subcategories

The relationships between faculty members' age and experience and the organizational climate (OCDQ-HE-Partial) subcategories were addressed by determining the correlation coefficient between the variables (Table 18). The Pearson product-moment correlation test indicated a statistically significant 
negative correlation between faculty members' age and the organizational climate subcategory Intimacy, $r(\mathrm{~N}=165)=-0.249, p<.01\left(r^{2}=0.062\right)$. However, the Pearson product-moment correlation test did not indicate statistically significant correlations between faculty members' age and the organizational climate subcategories of Production, Disengagement, and Consideration (Table 18).

The Pearson product-moment correlation test indicated a statistically significant positive correlation between faculty members' experience and the organizational climate subcategory Production, $r(\mathrm{~N}=165)=0.182, p<.05\left(r^{2}=\right.$ 0.033), and statistically negative correlations between faculty members' experience and Consideration, $r(\mathrm{~N}=165)=-0.227, p<.01\left(r^{2}=0.052\right)$, and Intimacy, $r(\mathrm{~N}=165)=-0.280, p<.01\left(r^{2}=0.078\right)$. However, the Pearson product-moment correlation test did not indicate a statistically significant correlation between faculty members' experience and the organizational climate subcategory of Disengagement. The relationship between faculty members' age and the OCDQ-HE-Partial subcategory of Intimacy and the relationship between faculty members' experience and the OCDQ-HE-Partial subcategories of Consideration and Intimacy were significant at the 0.01 level. The relationship between faculty members' experience and the OCDQ-HE-Partial subcategory Production was significant at the 0.05 level (Table 18). 
Table 18

Correlation Between Faculty Member Age and Experience and Organizational Climate Subcategories ( $N=165)$

\begin{tabular}{|c|c|c|c|c|c|c|c|}
\hline & & Age & Experience & Production & Disengagement & Consideration & Intimacy \\
\hline Age & $\begin{array}{l}\text { Pearson Correlation } \\
\text { Sig. (2-tailed) }\end{array}$ & 1 & & & & & \\
\hline Experience & $\begin{array}{l}\text { Pearson Correlation } \\
\text { Sig. (2-tailed) }\end{array}$ & $\begin{array}{l}0.518 \text { ** } \\
0.000\end{array}$ & 1 & & & & \\
\hline Production & $\begin{array}{l}\text { Pearson Correlation } \\
\text { Sig. (2-tailed) }\end{array}$ & $\begin{array}{l}0.081 \\
0.300\end{array}$ & $\begin{array}{l}0.182 \text { * } \\
0.019\end{array}$ & 1 & & & \\
\hline Disengagement & $\begin{array}{l}\text { Pearson Correlation } \\
\text { Sig. (2-tailed) }\end{array}$ & $\begin{array}{l}0.072 \\
0.358\end{array}$ & $\begin{array}{r}-0.081 \\
0.299\end{array}$ & $\begin{array}{l}-0.396 \text { ** } \\
0.000\end{array}$ & 1 & & \\
\hline Consideration & $\begin{array}{l}\text { Pearson Correlation } \\
\text { Sig. (2-tailed) }\end{array}$ & $\begin{array}{r}-0.130 \\
0.096\end{array}$ & $\begin{array}{l}-0.227 \text { * } \\
0.003\end{array}$ & $\begin{array}{l}-0.755^{* *} \\
0.000\end{array}$ & $\begin{array}{l}0.516^{* *} \\
0.000\end{array}$ & 1 & \\
\hline Intimacy & $\begin{array}{l}\text { Pearson Correlation } \\
\text { Sig. (2-tailed) }\end{array}$ & $\begin{array}{l}-0.249 * * \\
0.001\end{array}$ & $\begin{array}{l}-0.280 \text { ** } \\
0.000\end{array}$ & $\begin{array}{l}-0.617 \text { ** } \\
0.000\end{array}$ & $\begin{array}{l}0.424 \text { ** } \\
0.000\end{array}$ & $\begin{array}{l}0.668 \text { ** } \\
0.000\end{array}$ & 1 \\
\hline
\end{tabular}

${ }^{*}$ Correlation is significant at the 0.01 level

* Correlation is significant at the 0.05 level

Faculty Members' Age and Organizational Climate

The age of the faculty members participating in this study ranged from 28 years to 70 years with a mean of 48 years (Table 19). Of the 165 faculty members surveyed, seven (4\%) of the faculty members were in the $20-29$ age group. Twenty-nine (17\%) of the faculty members were in the $30-39$ age group. Forty-four (27\%) of the faculty members were in the $40-49$ age group. Sixty-eight (41\%) of the faculty members were in the $40-49$ age group. Sixteen (10\%) of the faculty members were in the 60-69 age group, and one (1\%) of the faculty members was in the $70+$ age group. Table 19 shows organizational climate (OCDQ-HE-Partial) distribution by faculty members' age groups. 
Table 19

Distribution of Faculty Members' OCDQ-HE Scores by Age ( $N=165)$

\begin{tabular}{|c|c|c|c|c|c|c|}
\hline & $\begin{array}{l}\text { Basic Inter } \\
\text { Highly } \\
\text { Negative } \\
(-84 \text { to }-57)\end{array}$ & $\begin{array}{l}\text { rpretation o } \\
\text { Mod. } \\
\text { Negative } \\
(-56 \text { to }-29)\end{array}$ & $\begin{array}{l}\text { Organizat } \\
\text { Slightly } \\
\text { Negative } \\
\text { (-28 to 0) }\end{array}$ & $\begin{array}{l}\text { nal Clima } \\
\text { Slightly } \\
\text { Positive } \\
\text { (1 to } 28)\end{array}$ & $\begin{array}{l}\text { (OCDQ- } \\
\text { Mod. } \\
\text { Positive } \\
\text { (29 to 56) }\end{array}$ & $\begin{array}{l}\text { HE) Scor es } \\
\text { Highly } \\
\text { Positive } \\
\text { (57 to } 84 \text { ) }\end{array}$ \\
\hline $\begin{array}{l}\text { OCDQ-HE } \\
\text { Age 20-29 }\end{array}$ & 0 & 0 & 2 & 4 & 1 & 0 \\
\hline $\begin{array}{l}\text { OCDQ-HE } \\
\text { Age } 30-39\end{array}$ & 0 & 0 & 4 & 21 & 4 & 0 \\
\hline $\begin{array}{l}\text { OCDQ- HE } \\
\text { Age } 40-49\end{array}$ & 0 & 0 & 13 & 27 & 4 & 0 \\
\hline $\begin{array}{l}\text { OCDQ-HE } \\
\text { Age 50-59 }\end{array}$ & 0 & 0 & 24 & 40 & 4 & 0 \\
\hline $\begin{array}{l}\text { OCDQ-HE } \\
\text { Age } 60-69\end{array}$ & 0 & 0 & 5 & 11 & 0 & 0 \\
\hline $\begin{array}{c}\text { OCDQ-HE } \\
\text { Age } 70+\end{array}$ & 0 & 0 & 0 & 1 & 0 & 0 \\
\hline
\end{tabular}

\section{Summary}

Chairs and faculty members in West Virginia State Community College System participated in this study to determine the relationship between the emotional intelligence competencies of chairs and faculty members' perceptions of organizational climate. Thirty-three chairs (83\%) completed the Emotional Quotient Inventory and 165 (51\%) of the faculty members completed the Organizational Climate Description Questionnaire for Higher Education (OCDQHE-Partial). Both groups provided demographic information related to age, gender, and total years of experience.

Data were entered and analyzed utilizing the Statistical Package for Social Sciences (SPSS), version 11, and an alpha level of .05 served as the level of significance for this study. The Pearson product-moment correlation was utilized to determine the strength and the direction of the relationship between chairs' 
emotional intelligence competencies and faculty members' perceptions of organizational climate. The demographic characteristics of chairs that were compared to faculty members' perceptions of organizational climate included age, gender, years of experience as chair, and years of experience as chair in the current department or division. The demographic characteristics of the faculty members that were compared to OCDQ-HE-Partial included age, gender, and years of teaching experience in the current department or division. Analyses were conducted using the Pearson product-moment correlation and the chisquare test of independence based on appropriate application for each analysis. Results for each research question are given as major findings. Results that provide other useful data not related to the research questions are reported as ancillary findings.

A statistically significant negative correlation was found between chairs' levels of emotional intelligence and faculty members' perceptions of organizational climate. As the emotional quotient score of the chairs increased, faculty members' perceptions of organizational climate decreased. Subsequently, the five emotional quotient (EQ) composite categories were compared to the four organizational climate (OCDQ-HE-Partial) subcategories, and significant correlations were found between the following categories of emotional quotient (EQ) and organizational climate (OCDQ): As EQ Intrapersonal scores increased, OCDQ Disengagement scores increased and Consideration scores decreased. As EQ Interpersonal, Stress, Adaptability, and General Mood scores increased, OCDQ Disengagement scores also increased. The statistically significant 
relationship found between the EQ General Mood and OCDQ Disengagement variables does not support the review of literature on the subject, which indicates that the mood of the leader can influence (positively affect) organizational climate.

A statistically significant positive correlation was found between chairpersons' age and their emotional intelligence competencies. This correlation indicated that as the age of chairpersons increased, total EQ-i scores also increased. The relationship between chairs' gender, years of experience, and years of experience in the current department or division were also examined, but no significant correlation was found between those variables and the chairs' emotional intelligence competencies.

A statistically significant negative correlation was found between chairpersons' age, years of experience, and years of experience in the current department or division and their faculty members' perceptions of organizational climate. These correlations indicated that as the age, years of experience, and years of experience in the current department or division of chairpersons increased, faculty members' perceptions of organizational climate decreased. The relationship between the chairpersons' age groups and their emotional intelligence competencies was also examined, and a statistically significant positive correlation was indicated between chairpersons' age groups and their emotional intelligence competencies. This correlation indicated that as the age of chairpersons increased, total EQ-i scores also increased. The relationship between chairpersons' gender and their faculty members' perceptions of 
organizational climate was also examined, and these data indicate that there is a statistically significant difference between OCDQ-HE-Partial scores for female chairpersons as compared to male chairpersons.

A statistically significant negative correlation was found between the faculty members' teaching experience in the current department or division and their perceptions of organizational climate. This correlation indicated that as the faculty members' teaching experience in the current department or division increased, their perceptions of organizational climate decreased. Subsequently, faculty members' age and experience were compared to the four organizational climate (OCDQ-HE-Partial) subcategories, and significant correlations were found between the following categories of organizational climate (OCDQ): As faculty member age increased, OCDQ Intimacy scores decreased. As faculty member experience increased, OCDQ Production scores increased and Consideration and Intimacy Scores decreased. The relationship between faculty members' age and gender were also examined, but no significant correlation was found between those variables and the faculty members' overall perceptions of organizational climate. 


\section{Chapter 5}

Summary, Conclusions, and Recommendations

This chapter presents the purpose of the study, a summary of procedures used during the study, a summary of descriptive data, a summary of findings, and conclusions. It concludes with a discussion of implications and recommendations for further research.

\section{Summary of Purpose}

This study examined the relationship between chairs' emotional intelligence competencies and their faculty members' perceptions of organizational climate. The following research questions guided the analyses of the data:

1. What relationship exists, if any, between the chairperson's levels of emotional intelligence competencies and organizational climate as perceived by faculty members in the department or division?

2. What relationship exists, if any, between (a) age, gender, years of experience as a chairperson, years of experience as chairperson in the current department or division, and (b) the emotional intelligence competencies of chairpersons and (c) organizational climate as perceived by faculty members in the departments or divisions?

3. What relationship exists, if any, between age, gender, years of teaching experience as a faculty member in the current department or division, and organizational climate as perceived by faculty members in the departments or divisions? 


\section{Summary of the Procedures}

The populations of this study were the division chairs $(\mathrm{N}=40)$ and their faculty members $(\mathrm{N}=326)$ employed by the West Virginia State community college system during the 2006-07 academic year. All the chairs and their faculty members were asked to participate in the study.

A self-report questionnaire, the Emotional Quotient Inventory (EQ-i), was administered to all of the division chairs employed by the West Virginia State community college system during the 2006-2007 academic year (Appendix A). The division chairs received an email message directing them to a Web site where they were allowed to access an online questionnaire designed to collect demographic data and the Bar-On EQ-i instrument (Appendix C). The email message to the chairs encouraged participation, explained the purpose of the study, and assured the anonymity of survey participants. Thirty-three (83\%) of the 40 division chairs participated in the survey.

The organizational climate description questionnaire for academic departments of colleges and universities (OCDQ-HE-Partial) was administered to all 326 faculty members in the West Virginia State community college system (Appendix B). Faculty members received an email message directing them to a Web site where they were allowed to access an online questionnaire designed to collect demographic data and the OCDQ-HE instrument (Appendix E). The email message to faculty encouraged participation, explained the purpose of the study, and assured the anonymity of participants. Fifty-one percent (165) of the 326 
faculty members participated in the survey. This return exceeds the $50 \%$ plus one response rate required for a study of this type (Kerlinger \& Lee, 2000).

This researcher used the Bar-On Emotional Quotient Inventory (EQ-i), which is a self-report instrument developed by Bar-On (1997), to assess emotional intelligence competencies of department chairs (Appendix A). The EQ-i has an average internal consistency coefficient (Cronbach alpha) of 0.76 and average test-retest coefficients of 0.85 and 0.75 for one and four month time periods, respectively for the South African sample (Bar-On, 1997). According to Bar-On (1997), nine types of validity studies have been conducted on the EQ-i over the past 17 years. These validity studies include content, face, factor, construct, convergent, divergent, criterion-group, discriminate, and predictive validity (BarOn, 1997). Results from these validation studies are summarized in over 60 pages in Bar-On's technical manual for the EQ-i (Bar-On, 1997).

Faculty members' perception of organizational climate was assessed by using the organizational climate description questionnaire for academic departments of colleges and universities (OCDQ-HE-Partial) developed by Berge Borrevik in 1972 (Appendix B). Lewis (1991) reported Cronbach alphas for the four OCDQHE-Partial subset climate domains as being 0.93 for consideration, 0.84 for intimacy, 0.68 for disengagement, and 0.71 for production emphasis. Factor analysis, using varimax rotation, established construct validity (Lewis, 1991). The results of Borrevik's (1972) and Lewis' (1991) research studies validated the OCDQ-HE-Partial as a satisfactory instrument to assess the organizational climate of academic departments. 
Data from both instruments and demographic data from chairs and faculty members were entered into a Microsoft Excel spreadsheet. These data were then systematically entered into the Statistical Package for Social Sciences (SPSS). SPSS was used to produce frequency tables, means, percentages, quartiles, and to conduct the Pearson correlations and chi-square tests. An alpha level of .05 was used to determine statistical significance.

\section{Summary of Descriptive Data}

Demographic data relative to the research questions were collected from each of the respondents. These data included age, gender, years of experience, and years of experience in the current division. Of the 33 chairs responding to the EQ-i, 11 (33\%) were male and $22(67 \%)$ were female. The age of the chair respondents ranged from 39 years to 71 years with a mean of 53 years. All of the chairs reported total years of administrative experience and years of administrative experience in the current department. The range of total experience was from 1 to 39 years with a mean of 9 years. The range of experience in the current department was from 1 to 39 years with a mean of 7 years. Of the faculty members responding to the OCDQ-HE-Partial $(\mathrm{N}=165), 63$ (38\%) were male and $102(62 \%)$ were female. The age of the faculty respondents ranged from 28 years to 70 years with a mean of 48 years. The range of teaching experience in the current department was from 1 to 37 years with a mean of 11 years. 


\section{Summary of Findings}

There were several findings from the analyses of the data collected in this study. A statistically significant negative correlation (1) was found between chairs' levels of emotional intelligence and faculty members' perceptions of organizational climate. As the emotional quotient score of the chairs increased, faculty members' perceptions of organizational climate decreased. Subsequently, the five emotional quotient (EQ) composite categories were compared to the four organizational climate (OCDQ-HE-Partial) subcategories, and significant correlations were found between the following categories of emotional quotient (EQ) and organizational climate (OCDQ): As EQ Intrapersonal scores increased, OCDQ Disengagement scores increased and Consideration scores decreased. As EQ Interpersonal, Stress, Adaptability, and General Mood scores increased, OCDQ Disengagement scores also increased. The statistically significant relationship found between the EQ General Mood and OCDQ Disengagement variables does not support the review of literature on the subject, which indicates that the mood of the leader can influence (positively affect) organizational climate. Ancillary findings in this study indicated that chairs scored in the average range on Total Emotional Quotient (EQ) as measured by the Emotional Quotient Inventory and the distribution of scores for chairs was typical of those in the normative sample (Bar-On, 1997).

A statistically significant positive correlation (2) was found between chairpersons' age and their emotional intelligence competencies. This correlation indicated that as the age of chairpersons increased, total EQ-i scores also 
increased. The relationship between chairs' gender, years of experience, and years of experience in the current department or division were also examined, but no significant correlation was found between those variables and the chairs' emotional intelligence competencies.

The relationship between the chairpersons' age groups and their emotional intelligence competencies was also examined, and a statistically significant positive correlation was indicated between chairpersons' age groups and their emotional intelligence competencies. This correlation indicated that as the age of chairpersons increased, total EQ-i scores also increased.

A statistically significant negative correlation (3) was found between chairpersons' age, years of experience, and years of experience in the current department or division and their faculty members' perceptions of organizational climate. These correlations indicated that as the age, years of experience, and years of experience in the current department or division of chairpersons increased, faculty members' perceptions of organizational climate decreased. The relationship between chairpersons' gender and their faculty members' perceptions of organizational climate was also examined, and these data indicate that there is a statistically significant difference (4) between OCDQ-HE-Partial scores for female chairpersons as compared to male chairpersons. In this study, faculty members perceive organizational climate to be more positive for female chairpersons than male chairpersons.

A statistically significant negative correlation (5) was found between the faculty members' teaching experience in the current department or division and 
their perceptions of organizational climate. This correlation indicated that as the faculty members' teaching experience in the current department or division increased, their perceptions of organizational climate decreased. Subsequently, faculty members' age and experience were compared to the four organizational climate (OCDQ-HE-Partial) subcategories, and significant correlations were found between the following categories of organizational climate (OCDQ): As faculty member age increased, OCDQ Intimacy scores decreased. As faculty member experience increased, OCDQ Production scores increased and Consideration and Intimacy Scores decreased. The relationship between faculty members' age and gender were also examined, but no significant correlation was found between those variables and the faculty members' overall perceptions of organizational climate.

\section{Conclusions}

Data collected as a part of this study were sufficient to support the following conclusions:

Research Question No. 1 - What relationship exists, if any, between the chairperson's levels of emotional intelligence competencies and organizational climate as perceived by faculty members in those departments or divisions?

There was a statistically significant relationship between chairperson's levels of emotional intelligence competencies and organizational climate as perceived by their faculty members. The Pearson Correlation Coefficient of -0.268 indicated a negative although weak relationship between chairperson's levels of emotional intelligence competencies and organizational climate as perceived by their 
faculty members. With this relationship, as chairperson's levels of emotional intelligence competencies increased, faculty members' perceptions of organizational climate decreased (became more negative).

Subsequent comparisons of the Emotional Quotient Inventory (EQ-i) composite categories of Intrapersonal, Interpersonal, Stress, Adaptability, and General Mood and the organizational climate subcategories of Production, Consideration, Intimacy, and Disengagement revealed similar relationships. With those comparisons, there was a statistically significant positive relationship between chairperson's Emotional Quotient (EQ) composite categories and the organizational climate subcategory of Disengagement. Pearson Correlation Coefficients for the EQ composite categories ranged from 0.195 to 0.350 and indicated a positive although weak relationship between chairperson's Emotional Quotient (EQ) composite categories and the organizational climate subcategory of Disengagement. With this relationship, as chairperson's EQ composite categories (emotional intelligence competencies) increased, faculty members' levels of Disengagement also increased, and their perceptions of organizational climate became more negative.

A significant negative relationship was also found between the EQ-i composite category of Intrapersonal and the organizational climate subcategory of Consideration. The Pearson Correlation Coefficient of -0.196 indicated a negative although weak relationship between chairperson's EQ composite category of Intrapersonal and the organizational climate subcategory of Consideration. With this relationship, as the chairperson's EQ-i composite 
category of Intrapersonal (emotional intelligence competencies) increased, faculty members' levels of Consideration decreased, and their perceptions of organizational climate became more negative.

Research Question No. 2 - What relationship exists, if any, between (a) age, gender, years of experience as a chairperson, years of experience as chairperson in the current department or division, and (b) the emotional intelligence competencies of chairpersons and (c) organizational climate as perceived by faculty members in those departments or divisions?

There was a statistically significant relationship between chairperson's age and their levels of emotional intelligence competencies. The Pearson Correlation Coefficient of 0.414 indicated a positive although weak relationship between chairperson's age and their levels of emotional intelligence competencies. With this relationship, as chairperson's age increased, their level of emotional intelligence competencies (EQ-i scores) became higher.

Subsequently, chairpersons' ages were sorted into age groups identified by Bar-On (1997), and group EQ means were determined. A statistically significant relationship between chairperson's age groups and their levels of emotional intelligence competencies was found. The Pearson Correlation Coefficient of 0.995 indicated a strong, positive relationship between chairperson's age groups and their EQ (emotional intelligence competencies) means. With this relationship, older chairperson's age groups demonstrated higher EQ (emotional intelligence competencies) means. 
There was not a statistically significant relationship found between chairpersons' years of experience as a chairperson or years of experience as chairperson in the current department or division, and their emotional intelligence competencies.

There was not a statistically significant relationship found between chairpersons' gender and chairpersons' emotional intelligence competencies. These data indicated that there was not a statistically significant difference between EQ-i scores for female chairpersons as compared to male chairpersons.

Statistically significant relationships were determined between chairperson's age and experience, and their faculty members' perception of organizational climate. Pearson Correlation Coefficients of -0.289 for age, -0.172 for total administrative experience, and -0.079 for administrative experience in the current department or division indicated negative although weak relationships between those chairpersons' variables and their faculty members' perception of organizational climate. With these relationships, as chairperson's age and experience increased, their faculty members' perception of organizational climate decreased (became more negative).

There was a statistically significant relationship found between chairpersons' gender, and their faculty members' perception of organizational climate. These data indicate that there is a statistically significant difference between OCDQ-HEPartial scores for female chairpersons as compared to male chairpersons, and that faculty members perceive organizational climate to be more positive for female chairpersons than male chairpersons. 
Research Question 3 - What relationship exists, if any, between age, gender, years of teaching experience as a faculty member in the current department or division, and organizational climate as perceived by faculty members in those departments or divisions?

There was not a statistically significant relationship found between faculty members' age and their overall perceptions of organizational climate. However, a statistically significant relationship was found between faculty members' experience and their overall perceptions of organizational climate. The Pearson Correlation Coefficient of -0.228 indicated a negative although weak relationship between faculty members' experience and their overall perceptions of organizational climate. With this relationship, as faculty members' experience increased and their overall perceptions of organizational climate decreased (became more negative).

Subsequent comparisons of faculty members' age and experience, and the organizational climate subcategories of Production, Consideration, Intimacy, and Disengagement revealed similar relationships. There was a statistically significant negative relationship found between faculty member's age and the organizational climate subcategory of Intimacy. The Pearson Correlation Coefficient of -0.249 indicated a negative although weak relationship between faculty members' age and the organizational climate subcategory of Intimacy. With this relationship, as faculty members' age increased, their levels of Intimacy decreased, and their perceptions of organizational climate became more negative. 
There was a statistically significant negative relationship found between faculty member's experience and the organizational climate subcategories of Consideration and Intimacy. The Pearson Correlation Coefficients of -0.227 for Consideration and -0.280 for Intimacy indicated a negative although weak relationship between faculty members' experience and the organizational climate subcategories of Consideration and Intimacy. With this relationship, as faculty members experience increased, their levels of Consideration and Intimacy decreased, and their perceptions of organizational climate became more negative.

There was also a statistically significant positive relationship found between faculty member's experience and the organizational climate subcategory of Production. The Pearson Correlation Coefficient of 0.182 for Production indicated a positive although weak relationship between faculty members' experience and the organizational climate subcategory of Production. With this relationship, as faculty members experience increased, their levels of Production also increased, and their perceptions of organizational climate became more negative.

There was not a statistically significant relationship found between faculty members' gender and their perceptions of organizational climate. These data indicated that there was not a statistically significant difference between OCDQHE-Partial scores for female faculty members as compared to male faculty members. 


\section{Discussion and Implications}

With Research Question 1, it was determined that as chairperson's levels of emotional intelligence competencies increased, their faculty members' perceptions of organizational climate became more negative. Subsequent comparisons between the Emotional Quotient Inventory (EQ-i) composite categories (including the composite category of General Mood) and the organizational climate (OCDQ-HE-Partial) subcategories also revealed as chairperson's EQ-i composite categories (emotional intelligence competencies) increased, their faculty members' perceptions of organizational climate became more negative.

A review of the literature indicates that a relationship exists between the emotional intelligence competencies of leaders and their subordinates attitudes and performance in the organization (Cooper \& Sawar, 1997; Cherniss \& Goleman, 2001; Goleman, 1995;1998; Goleman, Boyatzis, \& McKee, 2001; 2002; Lucas, 1994; \& Weisinger, 1998), and employees' perceptions of organizational climate are (positively) linked to the emotional competencies of the leader (George, 2000; Goleman, 2000; Goleman, Boyatzis, \& McKee, 2001; 2002). However, in this study there was a statistically significant negative relationship found between the emotional intelligence competencies of chairs and their faculty members' perceptions of organizational climate, and data from this study do not support literature on the subject. These results mirror Allen's (2003) research which indicated a statistically significant negative correlation between 
the emotional intelligence competencies of principals of elementary, middle, and secondary schools and their teachers' perceptions of school climate.

One aspect of emotional intelligence that has been found to be directly related to organizational climate is the mood of the leader (George, 2000; Goleman, Boyatzis, \& McKee, 2001; 2002). However, the results of this study do not support that research. A significant positive relationship was found between the emotional quotient (EQ) composite category of General Mood and the organizational climate subcategory of Disengagement. Subsequently, significant positive relationships were also found between EQ composite categories of Intrapersonal, Interpersonal, Stress, and Adaptability and the organizational climate subcategory of Disengagement. None of these relationships support the development of a positive organizational climate.

One possible explanation for this finding is that organizational climate factors identified in previous studies in the corporate and business sector may not be the same as those assessed by the OCDQ-HE-Partial. Perhaps the use of a different measure to assess organizational climate might yield different results. Another possible explanation is that faculty members' perceptions of organizational climate may not be related to the chair at all, but rather as Getzels and Guba (1957) suggest, a function of compatibility between the nature and needs of the individual (the ideographic dimension) and the goals of the organization (the nomethetic dimension). In other words, when the needs and/or personality of the individual are compatible with the roles and expectations of the formal 
organization, then factors such as perceptions of climate, job satisfaction, and performance are heightened (Getzels \& Guba, 1957).

Chairpersons' age and their emotional intelligence competencies were compared with Research Question 2. This correlation indicated that as the age of chairpersons increased, total EQ-i scores became higher. Subsequently, chairpersons' ages were sorted into age groups identified by Bar-On (1997), and group EQ means were determined. Chairpersons' age groups were compared to group EQ means, and this correlation indicated a strong positive relationship between chairperson's age groups and their EQ (emotional intelligence competencies) means. With this relationship, older chairperson's age groups demonstrated higher EQ (emotional intelligence competencies) means.

With Bar-On's (1997) study, the age results indicated that older groups scored significantly higher than the younger groups with the $40-49$ year age group demonstrating the highest mean. In this study, the 30-39 age group mean was 93; the 40-49 age group mean was 100; the 50-59 age group mean was 107; and the 60-69 age group scored significantly higher than the younger groups with a mean of 110 . These results indicate that emotional intelligence increases with age and therefore, changes throughout life (Bar-On, 1997; Bar-On \& Handley, 1999; \& Goleman, 1998).

Chairpersons' gender and their emotional intelligence competencies were also compared with Research Question 2. In this study, there were no significance differences in EQ scores between male and female chairs, and these results correspond with Bar-On's (1997) ANOVA results for age and 
gender effects on the Bar-On Emotional Quotient Inventory (EQ-i) which revealed "no significant differences between males and females in overall emotional intelligence." (p. 83)

Chairpersons' gender and their faculty members' perceptions of organizational climate were compared with Research Question 2. In this study, female chairpersons' organizational climate (OCDQ-HE-Partial) scores were significantly more positive than their male counterparts. In Allen's 2003 study of elementary, middle, and secondary school principals, a significant difference between teachers' perceptions of positive school climate for female principals as compared to male principals was also indicated. Female principals in Allen's study demonstrated higher school climate scores than their male counterparts (Allen, 2003).

Research (Hollander and Yoder, 1978; Eagly, Karau, \& Johnson, 1992) indicates that female administrators tend to emphasize interpersonal skills, participatory management, and a democratic approach to management, while males tend to adopt a more autocratic or directive leadership style. This may account for the more positive ratings of the female chairpersons' in this study. Perhaps male chairpersons in this study should receive staff development on interpersonal skills, participatory management, and a democratic approach to management.

With Research Questions 2 and 3, chairpersons' and faculty members' age and experience demographic variables were compared to faculty members' perceptions of organizational climate (OCDQ-HE-Partial). Ancillary comparisons 
of faculty members' age and experience demographic variables versus organizational climate (OCDQ-HE-Partial) subcategories were also conducted. From those analyses, it was determined that as chairpersons' and faculty members' age and experience increase, faculty members' perceptions of organizational climate became more negative. It would appear from these findings that older and more experienced chairs and faculty members are much less content with organizational climate than their younger counterparts. It appears that as chairs and faculty members begin to retire and leave the system, the organizational climate of departments or divisions may improve. The Negative Relationship Between EQ and Organizational Climate

In an attempt to explain the negative relationship between emotional quotient competencies (EQ) of chairpersons' and their faculty members' perceptions of organizational climate, the following explanations are offered: Having served as supervisor in both corporate and academic worlds, this researcher ascertains that unique norms exist between corporate and community college academic workplaces. In the corporate and business realm, workers typically produce and sell a common product, and they have many opportunities to work on teams and engage in team problem-solving activities. Corporate and business workers' incentives are directly linked to the products they produce and sell, and the business' success, and the cycle time for recognition and reward is relatively short. In a community college academic division, there are several unique academic departments that utilize different types of equipment and instructional methods to produce their unique products which are their program graduates. 
Teamwork seldom occurs with the exception of intermittent committee work, grant writing, and occasional task teams needed to solve sporadic division or departmental problems. Community college academic division chairs' and faculty members' incentives are not directly linked to the quality and number of graduates they produce, and the cycle time for recognition and reward is relatively long or occasionally nonexistent.

In the community college academic division work environment, the primary responsibilities of faculty members are to teach and advise their students and build their programs. Committee work, grant writing, and administrative duties are viewed as negative job characteristics by division faculty members because involvement in those activities draws them away from their primary responsibilities.

Even though this researcher emphasizes interpersonal skills and a democratic approach to management, solicitation for faculty member involvement and participation is seldom satisfied and on some occasions, the urgency of the situation may merit forced recruitment. It is this researcher's belief that without intervention, chairs' and faculty members' continued involvement with the norms and dynamics of a typical community college academic workplace may foster the creation of a negative organizational climate.

The following literature outlines the unique work environment of academic departments and supports this researcher's observations: According to Hecht, Higgerson, Gmelch, \& Tucker (1999), "full-time tenure track faculty typically perceive themselves as pursuing careers, and they are motivated to engage in 
activities that build their resumes or advance their professional reputations as teachers and scholars within the discipline." (p. 46) At the same time, these fulltime faculty may resist duties that seem to slow their progress toward tenure and promotion, and they may see things such as service activities and student recruitment and retention as jobs of the department chair. These full-time faculty members on occasion vocalize a desire to have the department chair make decisions and handle all paperwork, and they believe that they should be spared all of the administrative chores. Hecht, Higgerson, Gmelch, \& Tucker (1999) indicate that:

Current departmental governance policies and policies provide strong inhibitors to effective teamwork, and subcultures built on the traditions of autonomy, independence, and individual rewards render the building of a departmental collectivity difficult, if not impossible. At the university/college level, faculty may recognize the need to meet departmental challenges, but they are also aware that they receive recognition toward tenure and promotion for their individual research or teaching effort. Collective effort lacks a standard of value in the academy, and external pressures add to the penchant for fragmentation. (p. 118)

Given the tension between faculty autonomy and collective department interests, the department chair must move the department toward a collaborative and collective culture. According to Higgerson (1996, p. 36), "The department climate does not automatically mirror the campus climate but develops from the perceptions of department members. While campus conditions may influence 
these perceptions, it is the internal department conditions that ultimately shape faculty and staff perceptions." It is the responsibility of the department chair to establish and maintain a healthy department climate. Lucas (1994), states that: A challenging task for the chair is to help faculty identify departmental norms and to ask whether these norms work to the good or the determent of the department, and a transformational leader will know his or her organization's norms and culture very well but will also be willing to risk challenging those norms when they are negative or dysfunctional. (p. 52)

The literature indicates that faculty members are often motivated by activities that build their resumes or advance their professional reputations, and they may resist duties that seem to slow their progress toward tenure and promotion. Faculty members may also see things such as service activities and student recruitment and retention as jobs of the department chair, and some of the faculty members may expect the department chair to make all the decisions and handle all the paperwork and administrative chores. Department subcultures often exist which are built on the traditions of autonomy and independence (academic freedom) and individual rewards render the building of a departmental collectivity very difficult. These internal and external pressures foster fragmentation and the development of a negative organizational climate. However, with the realization of tension between faculty autonomy and collective department interests, the department chair must move the department toward a collaborative and collective culture. It is the responsibility of the department chair to establish and maintain a healthy department climate, and a transformational 
leader will know his or her organization's norms and culture very well and be willing to risk challenging those norms when they are negative or dysfunctional.

A recent study on emotional intelligence (Barling, Slater, \& Kellway, 2000) indicates that emotional intelligence is significantly related to the following factors of transformational leadership: idealized influence, inspirational motivation, and individualized consideration, and the current findings suggest that individuals higher in emotional intelligence are seen by their subordinates as displaying more leadership behaviors. Similarly, one would assume that there would be a significant positive relationship between those factors of transformational leadership and faculty members' perceptions of organizational climate. This tends to indicate the need for further investigation of the relationship between these variables.

Recommendations for Further Research

An analysis of the findings of this study has led to the following recommendations:

1. That the study be replicated with a representative sample from a larger population to provide more diversity and more widespread generalizability. 2. That the study be replicated and administered to the West Virginia State four-year institutions.

3. That research be conducted using a different measure of emotional intelligence, a different measure of organizational climate, or different measures for both variables. 
4. That research be conducted using the Bar-On EQ- $360^{\circ}$ measure of emotional intelligence and the organizational climate description questionnaire for academic departments of colleges and universities (OCDQ-HE-Partial) to determine the relationship, if any, between faculty members' perceptions of their chairs' emotional intelligence and faculty members' perceptions of organizational climate.

5. That research be conducted to determine the relationship, if any, between the emotional intelligence of chairs and transformational leadership.

6. That research be conducted to determine the relationship, if any, between chairs' emotional intelligence competencies and chairs' leadership styles.

7. That research be conducted to determine the relationship, if any, between chairs' emotional intelligence competencies and faculty members' job satisfaction. 


\section{REFERENCES}

Allen, L. (2003). The relationship between the emotional intelligence competencies of principals in the Kanawha county school system in West Virginia and their teachers' perceptions of school climate, Unpublished doctoral dissertation, West Virginia University, West Virginia.

Astin, A. \& Astin, H. (Eds). (2000). Leadership reconsidered: Engaging higher education in social change. Battle Creek, MI: W. K. Kellogg Foundation

Barling, J., Slater, F., \& Kelloway, E.K. (2000). Transformational leadership and emotional intelligence: An exploratory study. Leadership and Organizational Development Journal, 21, 157-161.

Bar-On, R. (1988). The development of a concept of psychological well-being. Unpublished doctoral dissertation, Rhodes University, South Africa.

Bar-On, R. (1997). Emotional quotient inventory technical manual. North Towanda, NY: Multi-Health Systems, Inc.

Bar-On, R. \& Handley, R. (1999). Optimizing people. New Braunfels, Texas: PRO-Philes Press.

Bar-On, R. \& Parker, J. (2000). The handbook of emotional intelligence. San Francisco, CA: Jossey-Bass.

Bensimon, E. M. (1989). The meaning of "good presidential leadership": A frame analysis. ASHA Reader on Organization and Governance in Higher Education.

Bensimon, E. M. (1990). The new president and understanding the campus: New directions for institutional research. San Francisco, CA: Jossey-Bass, Inc. 
Bennis, W. G., \& Nanus, B. (1985). Leaders: The strategies for taking charge. New York: Harper \& Row.

Bolman, L. \& Deal, T. (1997). Reframing organization: Artistry, choice, and leadership $-2^{\text {nd }}$ ed. San Francisco, CA: Jossey-Bass.

Borrevik, B. (1972). The construction of an OCDQ for academic departments in colleges and universities. Unpublished doctoral dissertation, University of Oregon.

Boyatzis, R.E., Goleman, D., \& Rhee, K. (2000). Clustering competence in emotional intelligence: Insights from the emotional competence inventory (ECI). In R. Bar-On \& J. D. A. Parker (Eds.). Handbook of Emotional Intelligence. (pp. 343-362). San Francisco: Jossey-Bass.

Burns, J. (1978). Leadership. New York: Harper \& Row.

Cherniss, C. \& Adler, M. (2000). Promoting emotional intelligence in organizations. Alexandria, VA: American Society for Training \& Development

Cherniss, C. \& Goldman, D. (2001). The emotional intelligence workplace. San Francisco, CA.: Jossey-Bass.

Cooper, R.K. \& Sawaf, A. (1997). Executive EQ: Emotional intelligence in leadership and organizations. New York, NY: Grosset/Putman.

Donahue, J.D. (1986). Faculty perceptions of organizational climate and expressed job satisfaction in selected baccalaureate schools of nursing. Journal of Professional Nursing, 2(6). 373-379. 
Eagly, A.L., Karau, S.J., \& Johnson, B.T. (1992). Gender and leadership style among school principals: A meta-analysis. Educational Administration Quarterly, 28, 76-102.

Feldman, D. (1999). The handbook of emotional intelligent leadership - Inspiring others to achieve results. Santa Fe, NM: Leadership Performance Press.

George, J.M. (2000). Emotions and leadership: The role of emotional intelligence. Human Relations, 53(8), 1027-1053.

Getzels, J.W. \& Guba, E.G. (1957). Social behavior and the administrative process. School Review, 65, 423-441.

Gillett-Karam, Rosemary. (1999). Midlevel management in the community college: A rose garden? New Directions for Community Colleges, No. 105, Volume XXVII, No. 1. San Francisco, CA.: Jossey-Bass, Inc.

Goleman, D. (1995). Emotional intelligence. New York, NY: Bantam Books.

Goleman, D. (1998). What makes a leader? Harvard Business Review, 76(6), 93102.

Goleman, D. (1998). Working with emotional intelligence. New York, NY: Bantam Books.

Goleman, D. (2000, March - April). Leadership that gets results. Harvard Business Review: On Point, 76-90.

Goleman, D., Boyatzis, R. \& McKee, A. (2001) Primal leadership: The hidden driver of great performance. The Harvard Business Review, December, $42-51$. 
Goleman, D., Boyatzis, R. \& McKee, A. (2002). Primal leadership: Realizing the power of emotional intelligence. Boston, MA: Harvard Business School.

Gulick, L. \& Urwick, L. (Eds.). (1937). Papers on the science of administration. New York Institute of Public Administration, (pp. 3-13).

Hackman, M., \& Johnson, C. (2000). Leadership a communication perspective. (Third Edition). Illinois: Waveland Press, Inc.

Halpin, A.W. and Croft, D.B. (1962). The organizational climate of schools.

Chicago: Midwest Administrative Center, The University of Chicago.

Hecht, I., Higgerson, M., Gmelch, W., \& Tucker, A. (1999).The department chair as academic leader. Phoenix, AZ: The American Council on Education and The Oryx Press

Higgerson, M. L. (1996). Communication skills for department chairs. Boston, MA: Anker Publishing Company, Inc.

Hollander, E.P., \& Yoder, J. (1978). Some issues in comparing women and men as leaders. (ERIC Document Reproduction Service No. ED175773).

Hopper, R. (2005). Emotional intelligence in academic library leadership. Library Staff Publications: Johnson \& Wales University Hoy, W. K., \& Miskel, C. G. (2001). Culture and climate in schools. In Educational Administration: Theory, Research, and Practice (6 $6^{\text {th }}$ Edition). (pp. 174-215). New York, NY: McGraw-Hill Companies, Inc.

Kerlinger, F.N. \& Lee, H.B. (2000). Foundations of behavioral research (4th ed.). Orlando, FL: Harcourt College Publishers. 
Kouzes, J. M., \& Posner, B. Z. (1995). The leadership challenge: How to get extraordinary things done in organizations. San Francisco: Jossey-Bass.

Leeper, R.W. (1948). A motivational theory of emotions to replace "emotions as disorganized responses." Psychological Review, 55, 5-21.

Lewis, J.H. (1991). An analysis of the relationship between the power orientation of deans and organizational climate in colleges and schools of nursing. Unpublished doctoral dissertation, University of Cincinnati.

Litwin, G.H. \& Stringer, R.A. (1968). Motivation and organizational climate. Boston, MA: Harvard University Press.

Lucas, A.F. (1994). Strengthening departmental leadership: A team-building guide for chairs in colleges and universities. San Francisco, CA: Jossey-Bass Publishers.

Maslow, A.H. (1950). Self-actualizing people: A study of psychological health. Personality, 1, 11-34.

Maslow, A.H. (1954). Motivation and personality. New York: Harper and Brothers.

Peters, T. J., \& Waterman, R. H. (1982). In search of excellence: lessons from america's best-run companies. New York: Harper \& Row.

Plake, B., Impala, I., \& Murphy, L. (Eds.). (2001). Bar-On emotional quotient inventory. In The Fourteenth Mental Measurements Yearbook (pp. 106-109). Lincoln, NE: Buros Institute of Mental Measurements. 
Seagren, Alan T., John W. Creswell, \& Daniel W. Wheeler. (1993). The department chair: New roles, responsibilities and challenges. ASHE-ERIC Higher Education Report No. 1. Washington, D.C.: The George Washington University, Graduate School of Education and Human Development.

Stogdill, R. (1948). Personal factors associated with leadership: A survey of the literature. Journal of Psychology, 25, 35-71.

Stogdill, R. (1948). Personal factors associated with leadership: A survey of literature. Journal of Psychology, 25, 64.

Wechsler, D. (1940). Nonintellective factors in general intelligence. Psychological Bulletin, 37, 444-445.

Weisinger, H. (1998). Emotional intelligence at work. San Francisco, CA: Jossey-Bass Publishers. 
APPENDICES 
Appendix A: Bar-On Emotional Quotient Inventory 


\section{BarOn Emotional Quotient Inventory}

by Dr. Reuven Bar-On

Introduction

The EQ-I consists of statements that provide you with an opportunity to describe yourself by indicating the degree to which each statement is true of the way you feel, think, or act most of the time and in most situations. There are five possible responses to each sentence.

1. Very seldom or Not true of me

2. Seldom true of me

3. Sometimes true of me

4. Often true of me

5. Very often true of me or True of me

Instructions

Read each statement and decide which one of the five possible responses best describes you. Mark your answer sheet by filling in the circle containing the number that corresponds to your answer.

If a statement does not apply to you, respond in such a way that will give the best indication of how you would possibly feel, think, or act. Although some of the sentences may not give you all the information you would like to receive, choose the response that seems the best, even if you are not sure. There are no "right" or "wrong" answers and no "good" or "bad" choices. Answer openly and honestly by indicating how you actually are and not how you would like to be or how you would like to be seen. There is no time limit, but work quickly and make sure that you consider and respond to every statement.

Following are sample items from the 133 item instrument:

1. My approach in overcoming difficulties is to move step by step.

24. I lack self-confidence.

48. Others find it hard to depend on me.

72. I care what happens to other people.

96. It's fairly easy for me to tell people what I think.

133. I responded openly and honestly to the above statements. 
MHS

Copyright@ 2001, Multi-Health Systems, Inc. All rights reserved. In the USA, P.O. Box 950, North Tonawanda, NY 14120-0950. 1-800-456-3003. In Canada, 3770 Victoria Park Ave., Toronto, ON M2H 3M6, 1-800-268-6011. Internationally, +1-416-492-3343 or 1-888-540-4484. 
Appendix B: Organizational Climate Description Questionnaire for Academic Departments in Colleges and Universities (OCDQ-HE) Partial 


\section{Organizational Climate Description Questionnaire for Academic Departments in Colleges and Universities (OCDQ-HE) Partial}

There are 42 statements in this questionnaire. The statements are descriptive of academic departments or similar administrative units in colleges and universities. The responses to this questionnaire will be used (1) to assess the relationships between the department head and faculty members, the relationships among faculty members, and (2) to describe the organizational climate of the departments.

\section{Directions:}

Please record your answer in the space provided below each of the items. In considering each item, go through the following steps:

a) Read the item carefully.

b) Think about the extent to which the item characterizes or occurs in your department (or similar administrative unit).

c) Below each item indicate the response you feel is correct:

1. Almost never occurs.

2. Infrequently occurs.

3. Approximately equal in occurrence and non-occurrence.

4. Frequently occurs.

5. Almost always occurs.

d) Respond to every item.

\section{Circle one response below each item.}

1. The department head puts the department's welfare above the welfare of any faculty member in it.
1. Almost never
2. Infrequently
3. Approx. equal
4. Frequently
5. Almost always

2. Faculty members recognize that there is a right and wrong way of going about department activities.
1. Almost never
2. Infrequently
3. Approx. equal
4. Frequently
5. Almost always

3. Faculty start projects without trying to decide in advance how they will develop or where they may end.
1. Almost never
2. Infrequently
3. Approx. equal
4. Frequently
5. Almost always 
4. The department head has faculty members share in making decisions.
1. Almost never
2. Infrequently
3. Approx. equal
4. Frequently
5. Almost always

5. The department head displays tact and humor.
1. Almost never
2. Infrequently
3. Approx. equal
4. Frequently
5. Almost always

6. Faculty members express concern about the "deadwood" in this department.
1. Almost never
2. Infrequently
3. Approx. equal
4. Frequently
5. Almost always

7. Scheduled appointments by faculty members are not kept.
1. Almost never
2. Infrequently
3. Approx. equal
4. Frequently
5. Almost always

8. There is a great deal of borrowing and sharing among the faculty.
1. Almost never
2. Infrequently
3. Approx. equal
4. Frequently
5. Almost always

9. The department head has everything going according to schedule.
1. Almost never
2. Infrequently
3. Approx. equal
4. Frequently
5. Almost always

10. The department head engages in friendly jokes and comments during department meetings.
1. Almost never
2. Infrequently
3. Approx. equal
4. Frequently
5. Almost always

11. The department head encourages the use of certain uniform procedures.
1. Almost never
2. Infrequently
3. Approx. equal
4. Frequently
5. Almost always

12. Faculty members talk about leaving the college or university.
1. Almost never
2. Infrequently
3. Approx. equal
4. Frequently
5. Almost always

13. The department head is first in getting things started.
1. Almost never
2. Infrequently
3. Approx. equal
4. Frequently 5. Almost always

14. The department head sells outsiders on the importance of his department.
1. Almost never
2. Infrequently
3. Approx. equal
4. Frequently
5. Almost always 
15. Faculty members seem to thrive on difficulty - the tougher things get, the harder they work.
1. Almost never
2. Infrequently
3. Approx. equal
4. Frequently
5. Almost always

16. Faculty members enjoy getting together for bowling, dancing, card games, etc.
1. Almost never
2. Infrequently
3. Approx. equal
4. Frequently
5. Almost always

17. Tensions between faculty factions interfere with departmental activities.
1. Almost never
2. Infrequently
3. Approx. equal
4. Frequently
5. Almost always

18. Close friendships are found among the department faculty.
1. Almost never
2. Infrequently
3. Approx. equal
4. Frequently
5. Almost always

19. The department head is friendly and approachable.
1. Almost never
2. Infrequently
3. Approx. equal
4. Frequently
5. Almost always

20. The department head finds time to listen to faculty members.
1. Almost never
2. Infrequently
3. Approx. equal
4. Frequently
5. Almost always

21. The department head accepts change in departmental policy or procedure.
1. Almost never
2. Infrequently
3. Approx. equal
4. Frequently
5. Almost always

22. The department yields to pressure of a few students who are not representative of student opinion.
1. Almost never
2. Infrequently
3. Approx. equal
4. Frequently
5. Almost always

23. Everyone enjoys their associations with their colleagues in this department.
1. Almost never
2. Infrequently
3. Approx. equal
4. Frequently
5. Almost always

24. The morale of the faculty members is high.
1. Almost never
2. Infrequently
3. Approx. equal
4. Frequently
5. Almost always

25. The department works as a committee of the whole.
1. Almost never
2. Infrequently
3. Approx. equal
4. Frequently
5. Almost always 
26. There are periodic informal social gatherings.
1. Almost never
2. Infrequently
3. Approx. equal
4. Frequently
5. Almost always

27. There are opportunities within the department for faculty members to get together in extra-curricular activities.
1. Almost never
2. Infrequently
3. Approx. equal
4. Frequently
5. Almost always

28. The department head changes his approach to meet new situations.
1. Almost never
2. Infrequently
3. Approx. equal
4. Frequently
5. Almost always

29. The important people in this department expect others to show respect for them.
1. Almost never
2. Infrequently
3. Approx. equal
4. Frequently
5. Almost always

30. Older faculty members control the development of departmental policy.
1. Almost never
2. Infrequently
3. Approx. equal
4. Frequently
5. Almost always

31. Faculty members ask permission before deviating from common policies or practices.
1. Almost never
2. Infrequently
3. Approx. equal
4. Frequently
5. Almost always

32. The department head maintains definite standards of performance.
1. Almost never
2. Infrequently
3. Approx. equal
4. Frequently
5. Almost always

33. Individual faculty members are always trying to win an argument.
1. Almost never
2. Infrequently
3. Approx. equal
4. Frequently
5. Almost always

34. The department head coaches and counsels faculty members.
1. Almost never
2. Infrequently
3. Approx. equal
4. Frequently
5. Almost always

35. The department head delegates the responsibility for departmental functions among the faculty.
1. Almost never
2. Infrequently
3. Approx. equal
4. Frequently
5. Almost always

36. New jokes and gags get around the department in a hurry.
1. Almost never
2. Infrequently
3. Approx. equal
4. Frequently
5. Almost always 
37. Faculty members approach their problems scientifically and objectively.
1. Almost neve
2. Infrequently
3. Approx. equal
4. Frequently
5. Almost always

38. Faculty members talk to each other about their personal lives.
1. Almost never
2. Infrequently
3. Approx. equal
4. Frequently
5. Almost always

39. The faculty uses parliamentary procedures in meetings.
1. Almost never
2. Infrequently
3. Approx. equal
4. Frequently
5. Almost always

40. The department head treats all faculty members as his equal.
1. Almost never
2. Infrequently
3. Approx. equal
4. Frequently
5. Almost always

41. The department is thought of as being very friendly.
1. Almost never
2. Infrequently
3. Approx. equal
4. Frequently
5. Almost always

42. Faculty members in this department use mannerisms, which are annoying.
1. Almost never
2. Infrequently
3. Approx. equal
4. Frequently
5. Almost always 
Appendix C: Chair Survey Introduction Letter 
Date:

Address:

Dear Department Chair,

My name is Paul Milhoan, and I am a doctoral student majoring in higher education administration at West Virginia University. In partial fulfillment of the requirements for my dissertation, I am conducting research to determine if a relationship exists between the emotional intelligence competencies of department chairs in the West Virginia State Community College System and their faculty members’ perceptions of organizational climate.

During the fall 2006 semester, I intend to survey the entire population of department chairs in the West Virginia State Community College System using a selfadministered multi-question, structured survey called the Bar-On Emotional Quotient Inventory (EQ-i). This validated instrument was developed by Bar-On (1997) to assess emotional intelligence competencies.

As a department chair at (community college name), I am inviting you to participate in this study. Specifically, I would like you to take the self-administered, 133 "brief" question Bar-On EQ-i survey on-line at (Web address). An email will be sent to you within the week, which will contain an active link to the secure survey site. Once you access the Webpage, the survey will take you approximately 30 - 40 minutes to complete. The Bar-On EQ-i survey is coded to protect your anonymity, and once you complete and submit your survey, your responses will be stored in a secure database.

It is important to emphasize that your name or any other information that may identify you individually will not be released in the reported results and will remain confidential. Your participation in this project is completely voluntary and, you may choose not to answer every question or discontinue your participation at any time without prejudice. If you have any questions, please feel free to contact me.

Sincerely,

Paul Milhoan

Doctoral Student

West Virginia University

Phone: (304) 424-8272

paul.milhoan@mail.wvu.edu 
Appendix D: Chairperson Demographics Survey 


\section{Chairperson Demographic Information}

Gender: Male $\square$ Female

Age

Years of Service in Current Division or Department

Years Service as Division or Department Chair

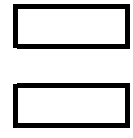


Appendix E: Faculty Member Survey Introduction Letter 
Date:

Address:

Dear Faculty Member,

My name is Paul Milhoan, and I am a doctoral student majoring in higher education administration at West Virginia University. In partial fulfillment of the requirements for my dissertation, I am conducting research to determine if a relationship exists between the emotional intelligence competencies of department chairs in the West Virginia State Community College System and their faculty members’ perceptions of organizational climate.

During the fall 2006 semester, I intend to survey the entire population of faculty members in the West Virginia State Community College System using a selfadministered multi-question, structured survey called the Organizational Climate Description Questionnaire for Academic Departments of Colleges and Universities (OCDQ-HE). This validated instrument was developed by Berge Borrevik (1972) to measure organizational climate at the higher education level.

As a faculty member at (community college name), I am inviting you to participate in this study. Specifically, I would like you to take the self-administered, 42 "brief" question OCDQ-HE survey on-line at (Web address). An email will be sent to you within the week, which will contain an active link to the secure survey site. Once you access the Webpage, the survey will take you approximately 30 - 35 minutes to complete. The OCDQ-HE survey is coded to protect your anonymity, and once you complete and submit your survey, your responses will be stored in a secure database.

It is important to emphasize that your name or any other information that may identify you individually will not be released in the reported results and will remain confidential. Your participation in this project is completely voluntary and, you may choose not to answer every question or discontinue your participation at any time without prejudice. If you have any questions, please feel free to contact me.

Sincerely,

Paul Milhoan

Doctoral Student

West Virginia University

Phone: (304) 424-8272

paul.milhoan@mail.wvu.edu 
Appendix F: Faculty Member Demographics Survey 
Faculty Member Demographic Information

Gender: Male $\square$ Female $\square$

Age

Years of teaching Experience in Current Division or Department 
Appendix G: EQ-i Individual Summary Report and Key 


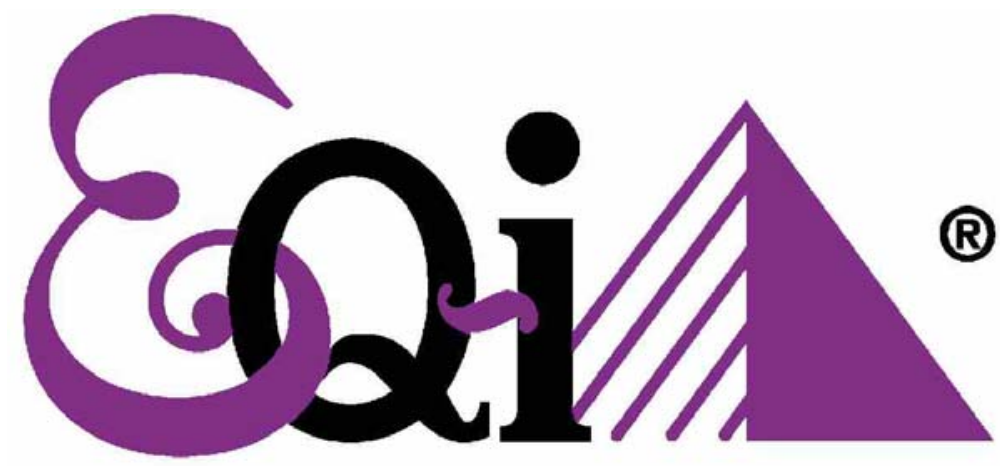

\section{BarOn Emotional Quotient Inventory}

By Reuven Bar-On, Ph.D.

\section{Individual Summary Report}

\section{Name: Example}

ID:

Age: 56

Gender: Male

Admin. Date: November 12, 2006 (Online)

Duration: 32 Minutes 18 Seconds

The information given in this report should be used as a means of generating hypotheses and as a guide to assessment. Higher standard scores are associated with greater levels of emotional intelligence and better performance. 100 represents effective emotional functioning. Scores greater than 100 represent enhanced emotional functioning, and scores of less than 100 indicate areas that may be improved. (The value -99 may appear if scores are incomputable due to missing item responses). 


\section{Total EQ}

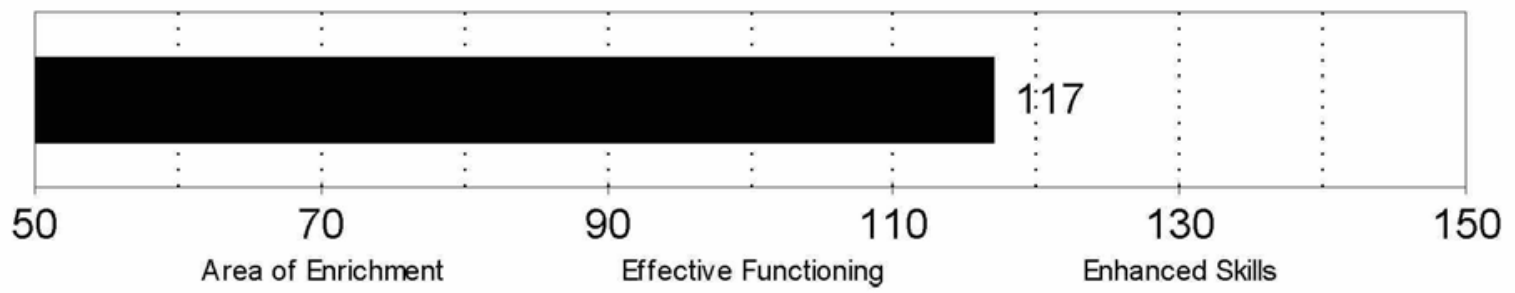

\section{Composite Scales}

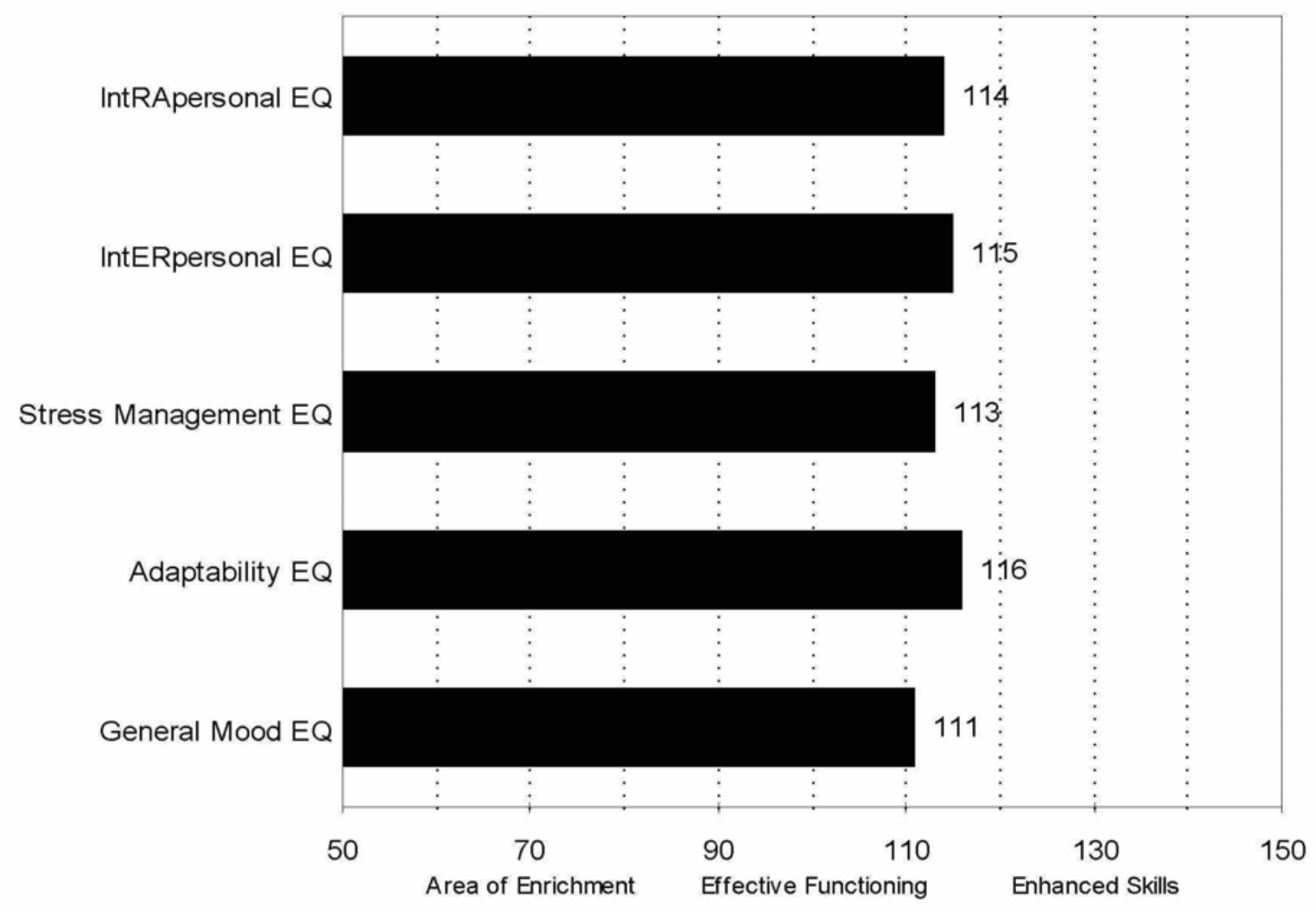




\section{Content Subscales Validity Indicators}

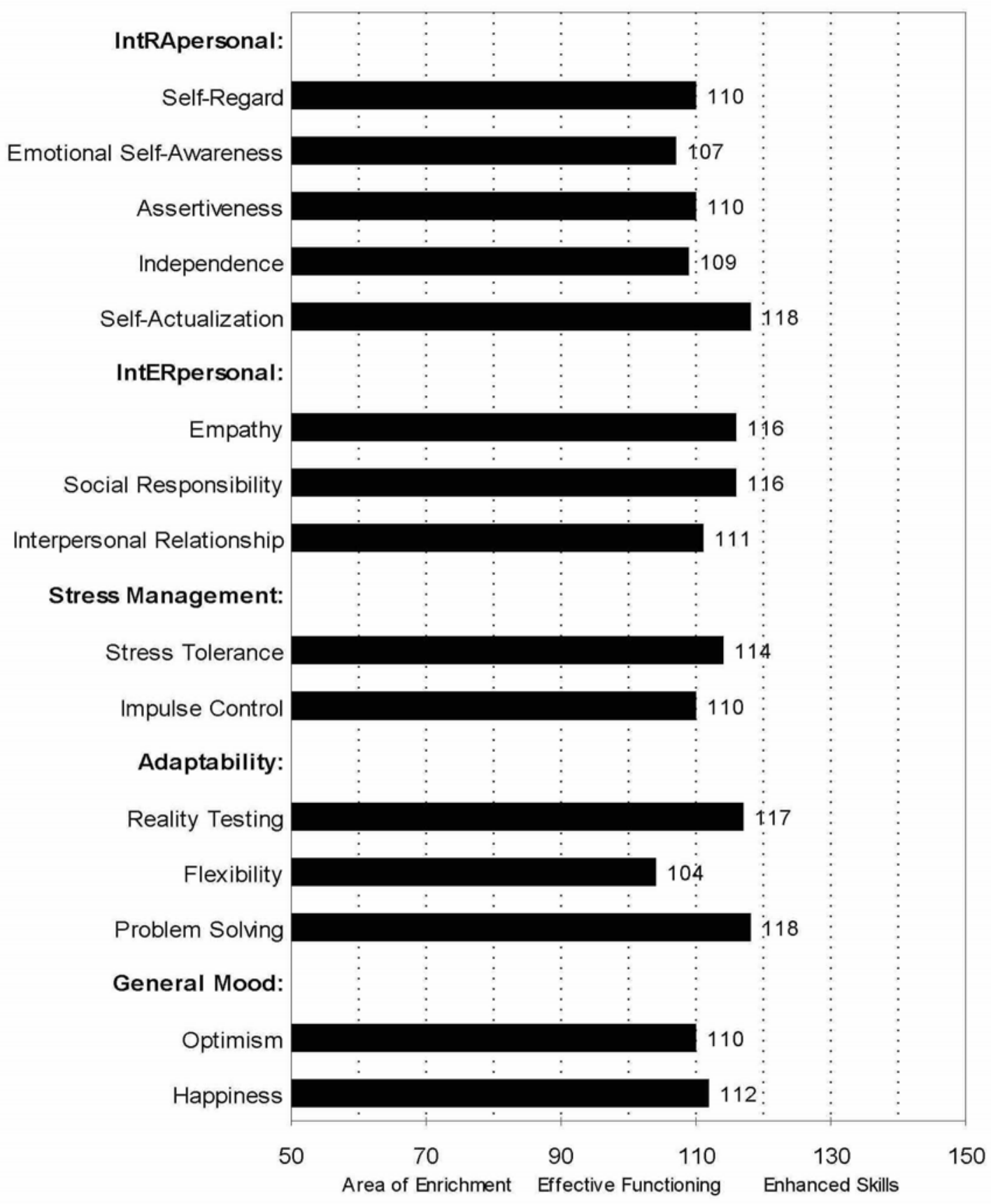




\section{Validity Indicators}

\section{Validity Comment:}

The validity indicators are all in the acceptable range suggesting valid responses and results that are not unduly influenced by response style.

Inconsistency Index: 1

Impression: $\quad$ Positive $=113$

Negative $=87$

Correction: $\quad$ Type I $=-2.37$, Type II $=-3.16$, Type III = -4.17 , Type IV = -4.96 , Type $V=-3.66$

\section{Positive Impression (PI) and Negative Impression (NI) Scores}

The scores obtained on the validity scales indicate a realistic and accurate self-appraisal which is not overly positive or negative. 


\begin{tabular}{|l|l|l|l|}
\hline Score Summary & Adjusted Score & Unadjusted Score & Guideline \\
\hline Inconsistency Index & & 1 & OK \\
Positive Impression & & 113 & OK \\
Negative Impression & & 87 & OK \\
TOTAL EQ: & 117 & $\mathbf{1 2 1}$ & High \\
INTRAPERSONAL: & $\mathbf{1 1 4}$ & $\mathbf{1 1 6}$ & High \\
Self-Regard & 110 & 115 & High \\
Emotional Self-Awareness & 107 & 109 & Average \\
Assertiveness & 110 & 110 & High \\
Independence & 109 & 109 & Average \\
Self-Actualization & 118 & 122 & High \\
INTERPERSONAL: & $\mathbf{1 1 5}$ & $\mathbf{1 1 9}$ & High \\
Empathy & 116 & 116 & High \\
Social Responsibility & 116 & 120 & High \\
Interpersonal Relationship & 111 & 114 & High \\
STRESS MANAGEMENT: & $\mathbf{1 1 3}$ & $\mathbf{1 1 8}$ & High \\
Stress Tolerance & 114 & 117 & High \\
Impulse Control & 110 & 114 & High \\
ADAPTABILITY: & $\mathbf{1 1 6}$ & $\mathbf{1 1 9}$ & High \\
Reality Testing & 117 & 120 & High \\
Flexibility & 104 & 106 & Average \\
Problem Solving & 118 & 120 & High \\
GENERAL MOOD: & $\mathbf{1 1 1}$ & $\mathbf{1 1 6}$ & High \\
Optimism & 110 & 114 & High \\
Happiness & 112 & 116 & High \\
\hline
\end{tabular}

Norm Type: General nonspecific 


\begin{tabular}{|c|c|c|c|c|c|c|c|c|c|}
\hline Item & Response & Item & Response & Item & Response & Item & Response & Item & Response \\
\hline 1 & 5 & 28 & 2 & 55 & 5 & 82 & 2 & 109 & 2 \\
\hline 2 & 2 & 29 & 5 & 56 & 1 & 83 & 1 & 110 & 5 \\
\hline 3 & 1 & 30 & 1 & 57 & 1 & 84 & 5 & 111 & 2 \\
\hline 4 & 5 & 31 & 5 & 58 & 1 & 85 & 5 & 112 & 5 \\
\hline 5 & 4 & 32 & 1 & 59 & 5 & 86 & 1 & 113 & 5 \\
\hline 6 & 5 & 33 & 4 & 60 & 5 & 87 & 2 & 114 & 4 \\
\hline 7 & 4 & 34 & 4 & 61 & 5 & 88 & 4 & 115 & 1 \\
\hline 8 & 5 & 35 & 2 & 62 & 4 & 89 & 5 & 116 & 2 \\
\hline 9 & 4 & 36 & 1 & 63 & 5 & 90 & 5 & 117 & 1 \\
\hline 10 & 2 & 37 & 3 & 64 & 1 & 91 & 1 & 118 & 2 \\
\hline 11 & 4 & 38 & 1 & 65 & 4 & 92 & 3 & 119 & 5 \\
\hline 12 & 1 & 39 & 4 & 66 & 1 & 93 & 2 & 120 & 5 \\
\hline 13 & 1 & 40 & 5 & 67 & 4 & 94 & 1 & 121 & 2 \\
\hline 14 & 1 & 41 & 1 & 68 & 1 & 95 & 5 & 122 & 3 \\
\hline 15 & 5 & 42 & 2 & 69 & 1 & 96 & 5 & 123 & 4 \\
\hline 16 & 5 & 43 & 3 & 70 & 1 & 97 & 1 & 124 & 4 \\
\hline 17 & 1 & 44 & 5 & 71 & 1 & 98 & 5 & 125 & 1 \\
\hline 18 & 2 & 45 & 5 & 72 & 5 & 99 & 5 & 126 & 1 \\
\hline 19 & 3 & 46 & 1 & 73 & 2 & 100 & 5 & 127 & 1 \\
\hline 20 & 4 & 47 & 5 & 74 & 4 & 101 & 1 & 128 & 2 \\
\hline 21 & 1 & 48 & 1 & 75 & 2 & 102 & 3 & 129 & 5 \\
\hline 22 & 2 & 49 & 1 & 76 & 1 & 103 & 2 & 130 & 1 \\
\hline 23 & 2 & 50 & 5 & 77 & 1 & 104 & 5 & 131 & 4 \\
\hline 24 & 2 & 51 & 1 & 78 & 5 & 105 & 5 & 132 & 1 \\
\hline 25 & 1 & 52 & 2 & 79 & 1 & 106 & 5 & 133 & 5 \\
\hline 26 & 4 & 53 & 2 & 80 & 5 & 107 & 1 & & \\
\hline 27 & 2 & 54 & 5 & 81 & 5 & 108 & 5 & & \\
\hline
\end{tabular}

5 = Very Often true of me or true of me, $4=$ Often true of me, $3=$ Sometimes true of me, 2 = Seldom true of me, 1 = Very Seldom true or not true of me, $0=$ Omitted Item
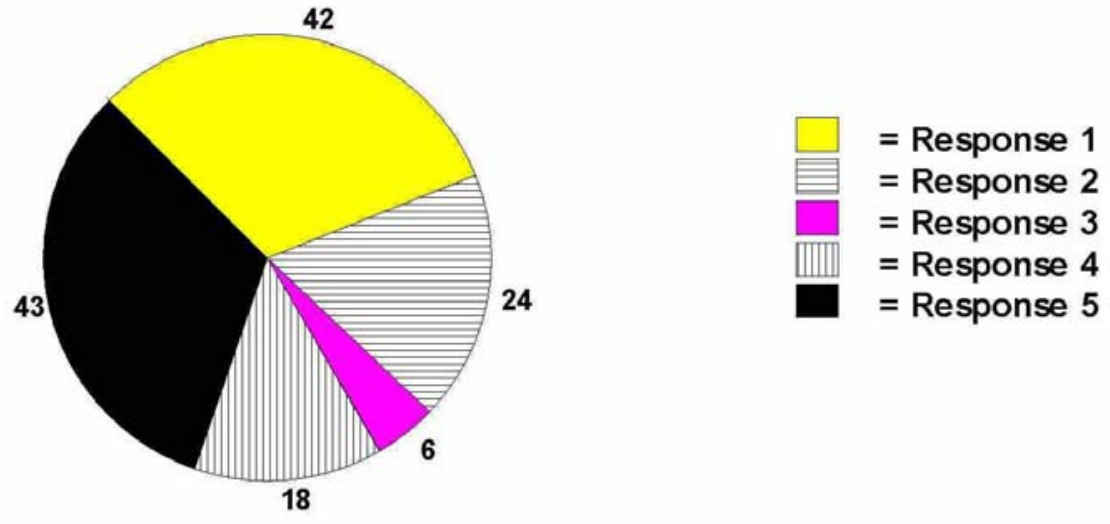
Date Printed: December 15, 2006

End of Report 
EQ-i 133 Composite Category Question Key

Intrapersonal:

Emotional Self-Awareness

7

9

23

35

52

63

88

116

Assertiveness

22

37

67

82

96

111

126

Self-Respect

11

24

40

56

70

85

100

114

129

Self-Actualization

\section{6}

21

36

51

66

81

95

110

125

Independence

3

19

32

48

92

107

121
Interpersonal:

Empathy

18
44
55
61
72
98
119
124
Interpersonal Relationship
10
23
31
39
55
62
69
84
99
113
128

Social

Responsibility

46

61

72

76

90

98

104

119

Adaptability:

Problem Solving

1

15

29

45

60

75

89

118

Reality Testing

8

35

38

53

68

83

88

97

112

127

Flexibility

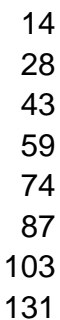

Stress Management:

Stress Tolerance

4

20

33

49

64

78

93

108

122

Impulse Control

13

27

42

58

73

86

102

117

130 


\section{EQ-i 133 Composite Category Question Key}

\section{General Mood:}

\section{Happiness}

$\begin{array}{rr}2 \\ 17 \\ 31 \\ 47 \\ 62 \\ 77 \\ 91 \\ 105 \\ \text { Optimism } & 120 \\ & 11 \\ & 20 \\ 26 \\ 54 \\ 80 \\ 106 \\ 108 \\ 132\end{array}$


Appendix H: OCDQ-HE-Partial Individual Summary Report and Key 


\section{OCDQ-HE (Partial)}

Organizational Climate Description Questionnaire for Academic Departments in Colleges and Universities (OCDQ-HE) Partial

\section{Individual Summary Report}

Name:

Age:

Gender:

Example

42

Male

Years of Teaching Experience in Current Department (Division) Admin. Date:

5

November 15, 2006

Overall OCDQ and OCDQ Subcategory Scores

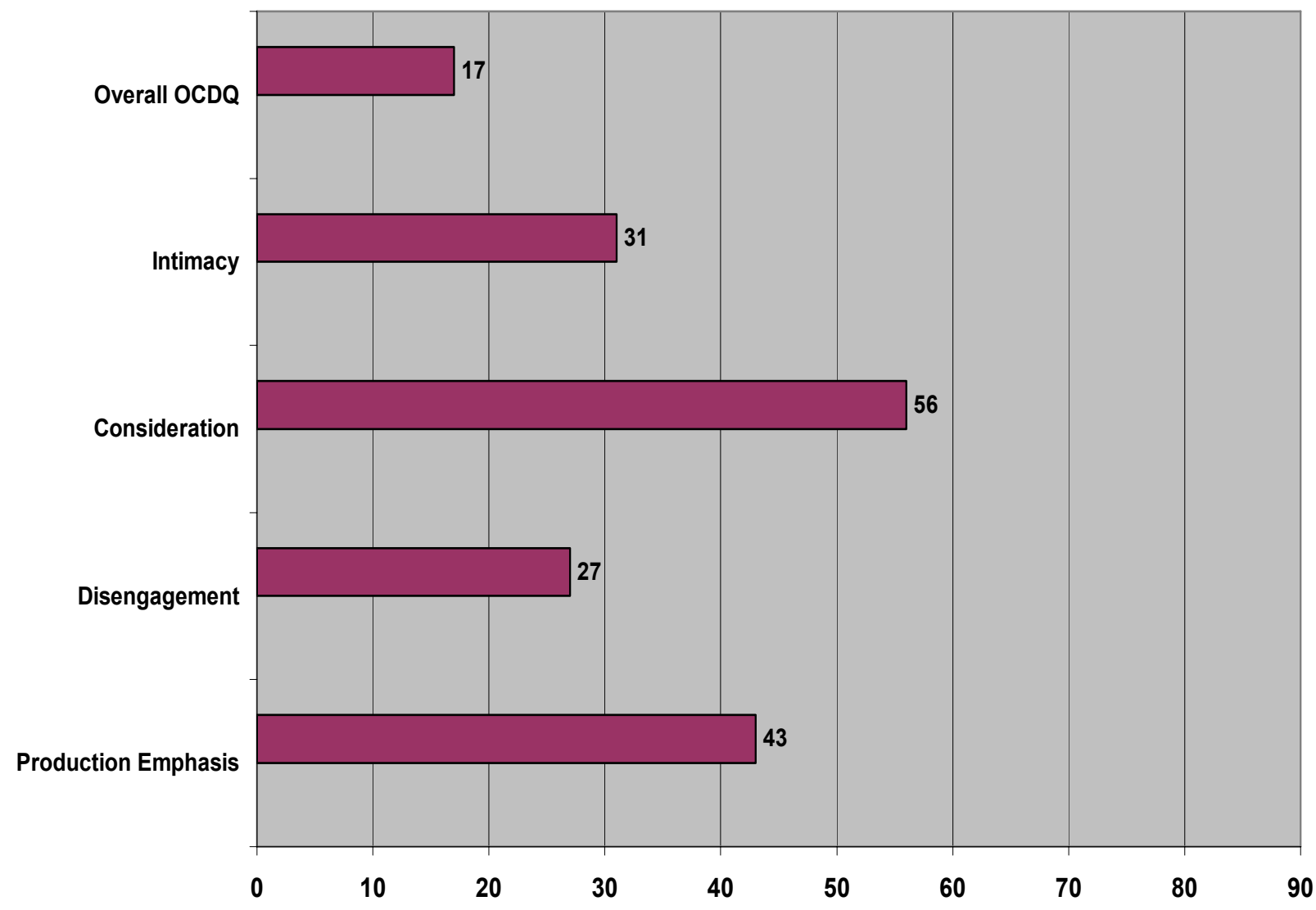




\begin{tabular}{|c|c|c|c|c|c|c|c|c|c|c|c|}
\hline Item & Response & Item & Response & Item & Response & Item & Response & Item & Response & Item & Response \\
\hline 1 & 5 & 8 & 4 & 15 & 5 & 22 & 1 & 29 & 4 & 36 & 3 \\
\hline 2 & 4 & 9 & 4 & 16 & 1 & 23 & 4 & 30 & 3 & 37 & 4 \\
\hline 3 & 2 & 10 & 5 & 17 & 2 & 24 & 4 & 31 & 4 & 38 & 5 \\
\hline 4 & 4 & 11 & 5 & 18 & 4 & 25 & 4 & 32 & 5 & 39 & 2 \\
\hline 5 & 5 & 12 & 2 & 19 & 5 & 26 & 4 & 33 & 4 & 40 & 5 \\
\hline 6 & 1 & 13 & 4 & 20 & 5 & 27 & 3 & 34 & 5 & 41 & 3 \\
\hline 7 & 2 & 14 & 5 & 21 & 5 & 28 & 4 & 35 & 5 & 42 & 2 \\
\hline
\end{tabular}

5 = Almost always, 4 = Frequently, 3 = Approx. equal, 2 = Infrequently, 1 = Almost never, 0 = Omitted

Intimacy Questions: $\quad 8,16,18,23,26,27,36,38$, and 41

Consideration Questions: $\quad 4,5,10,19,20,21,24,25,28,34,35$, and 40

Disengagement Questions: $3,6,7,12,17,22,29,30,33,37,42$

Production Emphasis Questions: 1, 2, 9, 11, 13, 14, 15, 31, 32, and 39

Overall OCDQ $=[($ Intimacy Scores + Consideration Scores) - (Disengagement Scores + Production Emphasis Scores)]

Date Printed: December 15, 2006

End of Report 
Consideration:

\section{OCDQ-HE (Partial) Question Key}

4. The department head has faculty members share in making decisions.

5. The department head displays tact and humor.

10. The department head engages in friendly jokes and comments during department meetings.

19. The department head is friendly and approachable.

20. The department head finds time to listen to faculty members.

21. The department head accepts change in departmental policy or procedure.

24. The morale of the faculty members is high.

25. The department works as a committee of the whole.

28. The department head changes his approach to meet new situations.

34. The department head coaches and counsels faculty members.

35. The department head delegates the responsibility for departmental functions among the faculty.

40. The department head treats all faculty members as equals.

\section{Intimacy:}

8. There is a great deal of borrowing and sharing among the faculty.

16. Faculty members enjoy getting together for bowling, dancing, card games, etc.

18. Close friendships are found among the department faculty.

23. Everyone enjoys their associations with their colleagues in this department.

26. There are periodic informal social gatherings.

27. There are opportunities within the department for faculty members to get together in extra-curricular activities.

36. New jokes and gags get around the department in a hurry.

38. Faculty members talk to each other about their personal lives.

41. The department is thought of as being very friendly.

\section{Disengagement:}

3. Faculty start projects without trying to decide in advance how they will develop or where they may end.

6. Faculty members express concern about the "deadwood" in this department.

7. Scheduled appointments by faculty members are not kept.

12. Faculty members talk about leaving the college or university.

17. Tensions between faculty factions interfere with departmental activities.

22. The department yields to pressure of a few students who are not representative of student opinion.

29. The important people in this department expect others to show respect for them.

30. Older faculty members control the development of departmental policy.

33. Individual faculty members are always trying to win an argument.

37. Faculty members approach their problems scientifically and objectively.

42. Faculty members in this department use mannerisms, which are annoying. 


\section{Production Emphasis:}

\section{OCDQ-HE (Partial) Question Key}

1. The department head puts the department's welfare above the welfare of any faculty member in it.

2. Faculty members recognize that there is a right and wrong way of going about department activities.

9. The department head has everything going according to schedule.

11. The department head encourages the use of certain uniform procedures.

13. The department head is first in getting things started.

14. The department head sells outsiders on the importance of his department.

15. Faculty members seem to thrive on difficulty - the tougher things get, the harder they work.

31. Faculty members ask permission before deviating from common policies or practices.

32. The department head maintains definite standards of performance.

39. The faculty uses parliamentary procedures in meetings. 
CURRICULUM VITA 


\title{
Paul L. Milhoan, Jr.
}

\author{
1733 Forest Hills Drive \\ Vienna, WV 26105 \\ Hm: (304) 295-9680 \\ e-mail:paul.milhoan@mail.wvu.edu
}

Over 25 years of experience in the quality assurance field. Work experience includes sample analysis utilizing wet chemistry and analytical instruments, environmental sampling, method research and development, laboratory management, and process improvement.

\section{EDUCATION}

West Virginia University, College of Human Resources \& Education, Morgantown, WV Doctorate of Educational Leadership Studies, anticipated May2007

Ohio University, College of Business, Athens, $\mathrm{OH}$

Masters of Business Administration with HR concentration, August 1998

G.P.A. -3.7

Wheeling Jesuit University, Wheeling, WV

Bachelor of Human Resource Management, August 1997

G.P.A. -3.7

\section{WORK HISTORY}

Technology Division Chair: August 2005 - Present, West Virginia UniversityParkersburg: Caperton Center for Applied Technology - Parkersburg, WV.

\section{Assistant Professor Technology/Director Board of Governors A.A.S. and Regents Bachelor of Arts Degrees}

1999 - Present, West Virginia University-Parkersburg: Caperton Center for Applied Technology - Parkersburg, WV.

- Taught the following classes: Electricity and Electronics, Industrial Safety, Industrial Sampling, Instrumental Analysis of Plastics, Introduction to Computing, Introduction to Plastics - Materials and Processing with laboratory, Miscellaneous Plastic Processes, Miscellaneous Process Equipment, Mold Design and Processing Strategies, Plastics Production Systems, Process Instrumentation, 
Research and Development in Plastics, Science and Engineering of Materials with laboratory, Process Control, Electrical Power Distribution, Reactions and Reactors/Distillation and Extraction, Solids Handling/Mixing and Drying/sampling, Statistical Process Control, Project Conception and Definition Organization and Implementation, Manufacturing Processes and materials, Introduction to Business, Marketing Research, and Portfolio Development.

- Implemented the SCANS 2000 SQC Module in the INDT233 "Statistical Process Control” course (First on campus), and coached and counseled my students as they researched and analyzed problem situations, defined possible problem solutions, and determined and presented the best solution to me in business presentations.

- $\quad$ Evaluated and selected textbooks for use in the plastics and processes courses

- $\quad$ Researched/prepared laboratory experiments for use in the plastics and processes laboratories

- Evaluated/upgraded/procured/maintained laboratory equipment for use in the plastics, processes, and quality assurance laboratories.

- Coordinated the installation/start-up of the plastic processing equipment used in the plastic processes laboratory

- Implemented a plastics recycling program to promote environmental awareness and provide regrind material for our plastics processing equipment.

- Developed the IPSI Curriculum (Syllabus) for the Introduction to Plastics Materials and Processing (PLAS 110) course.

- $\quad$ Evaluated the Manufacturing Processes curriculum to determine what courses could be consolidated, eliminated, or added in order to better meet the needs of our students and subsequently, the employers of our students.

- Advised/tutored students when necessary (academic standing, career decisions)

Human Resource Management Intern: 1997 - 1998, Internship at TS Trim Industries, Inc. (Interior automotive parts supplier for Honda and Isuzu automobiles) Athens, $\mathrm{OH}$.

- Interpreted the Family Medical Leave Act (FMLA), determined how the act affects TS Trim employees, and communicated that information to the employees. Assisted management in resolving employee grievances.

- Analyzed TS Trim's safety program and made recommendations for improvement.

- Determined TS Trim’s Lost Workday Injury and Illness (LWDII) rate and suggested ways to reduce it.

- Recommended that TS Trim purchase a HRIS system to develop an employee skills inventory database.

- Acted as an official witness during a sexual harassment hearing.

- Assisted management in developing a job position interview questionnaire.

- Coordinated hiring of new TS Trim personnel.

- Provided new TS Trim employee orientation.

- Assisted in the preparation of the HR department's annual budget. 
- Conducted and in-depth study of TS Trim's Workers' Compensation claims and safety incidents to determine the predominate types of worker injuries and associate injury frequency rates.

\section{Graduate Assistant, Marketing Department}

1997 - 1998, Ohio University, College of Business- Marketing Department, Athens, OH.

- Developed expense spreadsheets to track departmental costs

- Assisted professors in filming undergraduate marketing presentations

- Developed student grading spreadsheets

- Coordinated the distribution of the marketing department's primary information surveys

\section{Laboratory Analyst to Process Chemist}

1969 - 1995, CYTEC Industries, Inc. (formerly American Cyanamid Co.), Belmont, WV

\section{4 - 1995 Process Chemist}

- Observed the assigned processes (Units) and investigated process improvement.

- Monitored raw material usage and qualified new or existing raw materials.

- $\quad$ Set-up and monitored unit SPC/SQC programs.

- Determined procedures to rework off-grade product when necessary.

- Wrote/revised production detailed instructions and batch records to comply with ISO 9002 and OSHA 1910 directives. (Completed Quality Systems Auditing Course, Handley-Walker Co.)

\section{1 - 1994 Quality Control Lab Supervisor}

- Supervised up to 13 Laboratory Analysts.

- Approved/rejected finished products (Including pharmaceuticals) based on established specifications.

- Monitored Laboratory test precision/variability and product stability studies.

- Managed the Laboratory Core safety program.

- Encouraged, provided means for employee training/development, quality improvement, and self-directed task teams.

- Answered Sales/customer questions and complaints.

\section{7 - 1991 Special Analyst}

- Researched, developed, implemented, and provided training on new laboratory methods.

- $\quad$ Set-up laboratory test precision studies.

- Obtained and utilized SQC data.

- Maintained laboratory instruments and supplies. 
1969 - 1987 Laboratory Analyst/Shift Leader

- Analyzed and reported in-process and development sample results using wet chemistry and analytical instruments.

- Performed environmental testing which included air emissions, ground/well water, and particulate exposure sampling.

- Worked with products such as animal feed supplements, petroleum catalysts, pigments, surfactants, and organic chemicals such as UV absorbers, Anti-oxidants, and Thioesters.

- Utilized analytical equipment such as Gas/Liquid Chromatographs, UV-VIS/IR Spectrographs, Potentiometric titrimeters, Polarographs, and high temperature/pressure reactors.

\section{AWARDS \& HONORS}

- Half Scholarship, MBA Program, College of Business, Ohio University

- $\quad$ Phi Theta Kappa, College honor society

- Ohio University - 1998 MBA Program, Student Commencement Speaker (Elected by peers)

\section{ACTIVITIES}

- Member National Tech Prep Network (NTPN)

- Member Chamber of Commerce of the Mid-Ohio Valley

- Member Mid-Ohio Valley Maintenance Council

- Member Mid-Ohio Valley Community and Technical College Consortium

- Member Mid-Ohio Valley Tech Prep Consortium

- Senator WVU Faculty Senate (elected office)

- Member Dean's Academic Council

- Member WVU-P Safety Committee

- Member Enrollment Management Council

- Member WVU-P Outcomes Assessment Committee

- Member WVU-P Facility Planning Task Force

- Member Electrical Technology Program Advisory Committee

- Member Drafting Technology Program Advisory Committee

\section{REFERENCES}

Available upon Request 